\title{
Article \\ On Analytical Modeling of the Air Gap Field Modulation in the Brushless Doubly Fed Reluctance Machine
}

\author{
Yassine Benômar ${ }^{1,2, *(\mathbb{C}}$, Julien Croonen ${ }^{1}$, Björn Verrelst ${ }^{3}$, Joeri Van Mierlo ${ }^{1,2}$ and Omar Hegazy ${ }^{1,2}(\mathbb{D}$ \\ 1 Mobility, Logistics and Automotive Technology Research Centre (MOBI), Department of Electrical \\ Engineering and Energy Technology (ETEC), Faculty of Engineering, Vrije Universiteit Brussel (VUB), \\ 1050 Brussel, Belgium; Julien.Croonen@vub.be (J.C.); Joeri.Van.Mierlo@vub.be (J.V.M.); \\ Omar.Hegazy@vub.be (O.H.) \\ 2 Flanders Make, 3001 Heverlee, Belgium \\ 3 MECH Department, Vrije Universiteit Brussel (VUB), Pleinlaan 2, 1050 Brussel, Belgium; \\ Bjorn.Verrelst@vub.be \\ * Correspondence: Yassine.Benomar@vub.be
}

Citation: Benômar, Y.; Croonen, J.; Verrelst, B.; Mierlo, J.V.; Hegazy, O. On Analytical Modeling of the Air Gap Field Modulation in the Brushless Doubly Fed Reluctance Machine. Energies 2021, 14, 2388. https://doi.org/10.3390/en14092388

Academic Editor: Anouar Belahcen

Received: 28 February 2021

Accepted: 19 April 2021

Published: 22 April 2021

Publisher's Note: MDPI stays neutral with regard to jurisdictional claims in published maps and institutional affiliations.

Copyright: (C) 2021 by the authors. Licensee MDPI, Basel, Switzerland. This article is an open access article distributed under the terms and conditions of the Creative Commons Attribution (CC BY) license (https:// creativecommons.org/licenses/by/ $4.0 /)$.

\begin{abstract}
The brushless doubly fed reluctance machine (BDFRM) is receiving an increased amount of attention from the research community thanks to its potential as an alternative drive for variable speed applications, both as motor and generator. Currently, the sizing of the BDFRM in the literature is based on the model of an ideal axially laminated rotor (ALR) and discrepancies are hidden in compensation factors which are in turn tuned with a finite element analysis (FEA). This paper proposes an analytical framework to accurately model the air gap field modulation, and by extension the torque density, of the BDFRM with ducted segmental rotor (DSR) and salient pole rotor (SPR). The results are verified with FEA and validated on a BDFRM prototype.
\end{abstract}

Keywords: BDFRM; magnetic design; variable speed drive; reluctance; electrical machines; machine design

\section{Introduction \\ 1.1. Literature Review}

The brushless doubly fed reluctance machine (BDFRM), with a reluctance rotor, was first announced as a 'new' machine type by Liang [1], due to its doubly AC excited nature, as an alternative for the self-cascaded induction machines with wound rotors, also named the brushless doubly fed induction machine (BDFIM). Both types of machine combine two three-phase stator windings of different pole numbers onto the same stator-rotor unit. One winding, the primary or grid winding (further denoted with subscript $g$ ), is connected to the grid supply, while the other, the secondary or control winding (denoted with subscript $c$ ), is connected to a (bidirectional) converter. These machines are of interest thanks to their slip recovery nature, meaning that the active power flow is divided between the grid and control winding. When operated in a limited speed range, it is possible to use a partially rated converter, which lowers the costs of the drive system. This makes these machine types attractive for variable speed applications such as pumps [2], wind power applications $[3,4]$ and heating, ventilation and air conditioning (HVAC). Previous studies proposed the BDFRM in a variety of power ranges, from $45 \mathrm{~kW}$ to $320 \mathrm{~kW}$ for pumps and small wind turbines [5,6], up to 1.5-2 MW for larger wind turbines and even turbo-electric propulsion systems $[3,7]$.

The self-cascaded induction machine was proposed for the first time by Hunt [8], more than a century ago, to omit the disadvantages of sliprings while still being able to perform speed control by resistance control. The Hunt machine is the oldest precursor of both the BDFRM and the BDFIM as they are known today and was particularly interesting for low-speed applications. About 50 years later, in the early 1970s, Broadway studied the 
self-cascaded induction machine ([9-12]) and introduced improvements to the BDFIM-rotor design with a nested-loop rotor, increasing the robustness and simplicity of the motor. He also conducted research on reluctance rotor variants and performed experimental tests, but only in the two special cases where (i) the control winding is short-circuited (asynchronous operation mode) and (ii) the control winding is excited with a DC voltage (synchronous operation mode). In these two cases, there is no need for a converter to be connected to the control winding. Broadway, however, mentioned the possibility of operating the reluctance variants in a doubly AC excited manner. The earliest developments on the doubly fed machines were focused on the BDFIM. Jovanović states in [2] that this is due to the limited capabilities, at the time, to generate a rotor with a saliency ratio high enough to make the BDFRM competitive compared to the BDFIM. However, the BDFRM has several advantages with respect to the BDFIM: while having no Ohmic losses in the rotor it has a potentially higher efficiency, it is easier to model and to control than the BDFIM and the BDFRM allows decoupled control of the active and reactive power [2,13-16]. The BDFRM can have superior performance over the BDFIM and has a better performance for adjustable speed applications [14].

Extensive research has led to several possibilities in rotor design, depicted in Figure 1, and a variety of control strategies [17,18]. All these rotors have the function to distort and modulate the field distribution in the air gap, thereby introducing coupling between the two stator windings of different spatial frequencies, i.e., windings with a different pole pair number. This coupling has a direct impact on the torque density and the active and reactive power flow and can differ strongly between the different rotor designs. A first distinction can be made based on how the rotor material is stacked, resulting radially laminated rotors, depicted in Figure $1 \mathrm{a}-\mathrm{c}$ and the axially laminated rotor (ALR), depicted in Figure 1d, treated by [2] as a BDFRM. In ALRs, the flux guides consist of a stack of axial laminates of magnetic iron, electrically and magnetically insulated from each other. This kind of rotor is also found in studies of the synchronous reluctance machine (SynRM) and are known for their superior saliency and thus superior performance. However, the ALR is less suited for industrial production than other rotor types [19]. Furthermore, studies show that the ALR is prone to high eddy currents resulting in important iron losses in the rotor $[19,20]$. These iron losses are expected to be even more pronounced for the BDFRM than for the SynRM. This is since in steady state, the SynRM rotor rotates synchronously with the fundamental component of the induced magnetic field and thus 'sees' a constant field. On the contrary, the BDFRM rotor does not rotate synchronously with either induced fields of the stator windings, it thus continuously 'sees' a rotating field and is as such more prone to eddy currents.

The radially laminated rotor comes in four different shapes in a BDFRM. The salient pole rotor (SPR) in Figure 1a, the ducted rotor (DR) in Figure $1 \mathrm{~b}$ and the segmental rotor (SR) in Figure 1c, which was theoretically treated by [9]. The SPR is an interesting rotor to analytically derive the working principle of the BDFRM, but is less performant with respect to others, due to a poor power factor and a high leakage inductance [21,22]. 
Radially Laminated

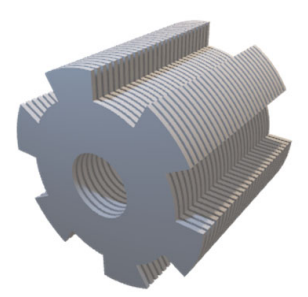

(a) Salient pole rotor (SPR)

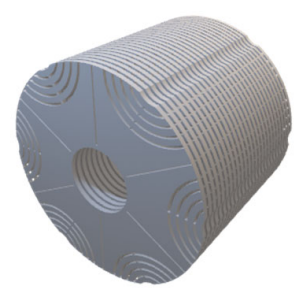

(b) Ducted rotor (DR)

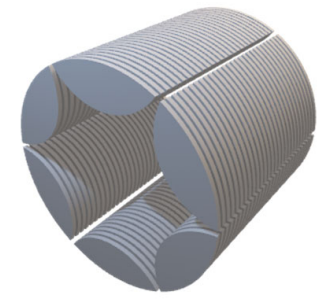

(c) Segmental rotor (SR)
Reluctance Rotors

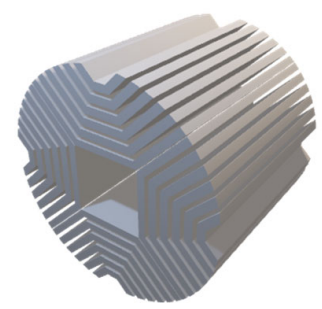

(d) Axially Laminated rotor (ALR)

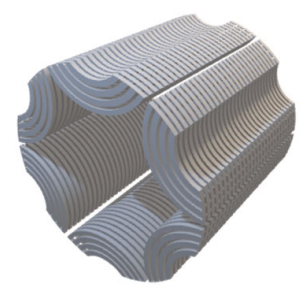

(e) Ducted Segmental rotor (DSR)

Figure 1. Different reluctance rotor types used for the BDFRM.

The DR introduces a preferred (low reluctance) path for the flux but consists of a complete magnetic iron rotor that is radially laminated in which so called barriers or ducts (of air) are cut or punched out to create the flux guides. This rotor type was first developed and patented by Vagati $[19,23,24]$ and is nowadays the reference rotor type for SynRMs. The DR figures in many proposed BDFRM designs [7,25-27]. The ducted segmental rotor (DSR), which is receiving growing attention [18,22,28-32], is closely related to the DR and is a combination of the SR and the DR. Both DR and DSR are preferred over the SPR and the ALR with a better coupling between the stator windings and no excessive iron losses $[15,27,33]$. In fact, the DSR is closely related to the DR in a way that bridges connecting different segments of flux ducts in the DR are designed to be saturated at rated conditions, thereby behaving as air and magnetically insulating the adjacent flux guides from each other. These bridges in the DR are needed to ensure the structural integrity of the iron stack, mounted on a round shaft, whereas for the DSR, the shaft is adapted to accommodate different segments. This comes at the cost of the mutual coupling due to leakage flux needed to saturate the bridges for the DR on the one hand, and a more complex shaft design for the DSR on the other hand.

The mutual coupling between the two stator windings, if dependent on the rotor position, leads to a change in coenergy, and thus reluctance torque generation. To obtain this coupling, the air gap field modulation performed by the reluctance rotor must modulate the field, induced by one of the two stator windings, to create sideband harmonics. These harmonics must coincide with the field of the other stator winding with different pole pair number. The rotor is thus especially designed to obtain a rotor position dependent mutual coupling and its number of poles must comply to Equation (1), where $\mathrm{p}_{\mathrm{r}}$ is the number of poles or segments on the rotor and $p_{g}$ and $p_{c}$ are the pole pair numbers of the grid and control winding, respectively. To generate a constant reluctance torque in steady state operation, the BDFRM also must comply to Equation (2). The different sign possibilities in Equation (1) are part of the design choices to be made. The sign in Equation (1) directly 
impacts the one in Equation (2). For further reading on the working of the BDFRM with an SPR based on the winding function theory, two other studies $[34,35]$ are suggested.

$$
\begin{aligned}
& p_{r}=\left|p_{g} \pm p_{c}\right| \\
& \Omega_{r}=\frac{\omega_{g} \pm \omega_{c}}{p_{r}}
\end{aligned}
$$

\subsection{Hypothesis and Paper Subject}

The sizing for machines with DR or DSR is based on the model for an ideal ALR. This type of rotor is known to have superior performance compared to other reluctance rotor types due to its ideal nature and because eddy currents are not considered in the model. However, this approach results in a significant under sizing of the machine when designing for torque. Until now, engineers have attributed this discrepancy to saturation and magnetic potential drops in the iron rotor core and introduced a saturation factor $k_{\text {sat }}$ to compensate for it. The latter is then estimated using a finite element analysis (FEA). However, even though saturation and magnetic potential drops are expected to attenuate the overall performance of the BDFRM, it is believed that these alone cannot possibly be the cause of this important degradation in performance and therefore, an underlying theoretical explanation should exist.

This paper aims to give a detailed overview of the analytical modeling of the BDFRM and proposes a new analytical approach to have a better estimate of the BDFRM torque density. First, a spectral analysis is carried out on the ideal ALR and its coupling factors are derived. The DSR with single flux guide and the SPR are then treated in a similar way and the resulting coupling factors are compared to FEA results and inductance measurements on a prototype.

\section{Analytical Modeling of Different Rotor Topologies}

\subsection{Spatial Frequency Analysis}

\subsubsection{Ideal ALR}

An early study of the BDFRM in [2] explored the use of an ALR. However, the modeling was mainly based on expressions of inductances derived with the winding function theory. Almost a decade later, the first idea of flux modulation was emitted in [36] where the flux density in the air gap is described by a modulo function. This idea was developed analytically further in $[22,29,37]$ following the magneto-motive force (MMF) modulation theory.

In this model, the rotor consists of conductors for magnetic flux with infinitesimal thickness that are laid out in a concentric way as depicted in Figure 2. The conductors are assumed to be ideal; this entails (i) that no magnetic flux flows from one conductor to the other and (ii) that no MMF drop occurs inside the material. In this case, Gauss's law imposes that the radial component of the air gap flux density at the surface between the rotor and the air gap relate by Equation (3). Furthermore, one set of concentric conductors are insulated from the neighboring sets. The parameter $p_{r}$ indicates the total number of rotor segments.

$$
\mathrm{B}_{\mathrm{r}}\left(\theta_{\mathrm{i}}\right)=-\mathrm{B}_{\mathrm{r}}\left(\frac{2 \pi}{\mathrm{p}_{\mathrm{r}}}-\theta_{\mathrm{i}}\right) \theta_{\mathrm{i}} \in\left[0, \frac{2 \pi}{\mathrm{p}_{\mathrm{r}}}\right]
$$




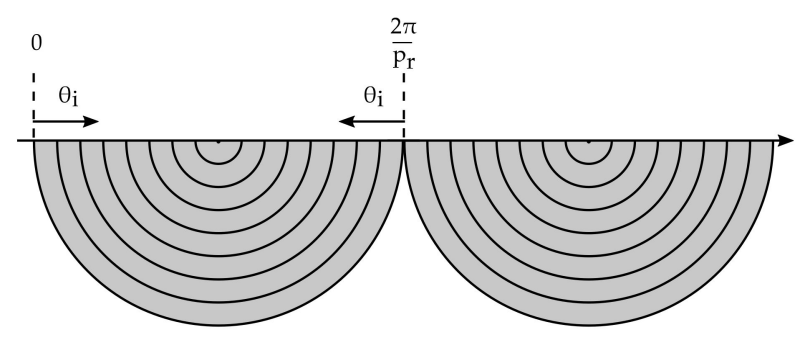

Figure 2. Ideal axially laminated rotor. The flux channels appear to have a finite thickness but are assumed to have an infinitesimal thickness in the model.

The resulting magnetic flux density in the air gap, can be expressed in terms of stator MMF (A.4), as derived in Appendix A. The influence of the rotor on the magnetic flux density can thus be reflected to the MMF and be modeled as an equivalent machine with a full iron rotor and a modulated stator MMF Equation (4).

$$
\mathrm{F}_{\mathrm{m}}\left(\theta_{\mathrm{i}}\right)=\frac{\mathrm{F}\left(\theta_{\mathrm{i}}\right)-\mathrm{F}\left(\frac{2 \pi}{\mathrm{p}_{\mathrm{r}}}-\theta_{\mathrm{i}}\right)}{2}
$$

In fact, $F\left(\frac{2 \pi}{p_{r}}-\theta_{i}\right)$ is the mirrored image of $F\left(\theta_{i}\right)$ with respect to the center of the rotor segment. The expressions Equations (3) and (4) are expressed in a local reference system with $\theta_{i}$ for each set $i$ of concentric laminations. For the entire air gap circumference, the modulated MMF wave is expressed by Equation (5). The modulation with a pulse function (The normalized sinc function is considered here: $\left.\operatorname{sinc}(k)=\frac{\sin (k \pi)}{k \pi}\right)$ will ensure that the mirrored image of $\mathrm{F}$ will only be accounted for over the rotor segment $i$. The origin in Figure 2, is the $d$-axis, i.e., the rotor axis of minimum reluctance, is shifted with $\theta_{\mathrm{r}}$ to account for the change in rotor position.

$$
\begin{gathered}
\mathrm{F}_{\mathrm{m}}\left(\theta, \theta_{\mathrm{r}}\right)=\frac{1}{2} \mathrm{~F}(\theta)-\frac{1}{2} \sum_{\mathrm{i}=0}^{\mathrm{p}_{\mathrm{r}}-1} \mathrm{~F}\left((2 \mathrm{i}+1) \frac{2 \pi}{\mathrm{p}_{\mathrm{r}}}-\theta+2 \theta_{\mathrm{r}}\right) \cdot \operatorname{pulse}\left(\theta-(2 i+1) \frac{\pi}{\mathrm{p}_{\mathrm{r}}}-\theta_{\mathrm{r}}\right) \\
\operatorname{pulse}(\theta)=\frac{1}{\mathrm{p}_{\mathrm{r}}}\left(1+\sum_{\mathrm{k}=1}^{\infty} 2 \sin \mathrm{c}\left(\frac{\mathrm{k}}{\mathrm{p}_{\mathrm{r}}}\right) \cos (\mathrm{k} \theta)\right)=\left\{\begin{array}{cc}
1 & \text { if } \theta \in\left[-\pi / \mathrm{p}_{\mathrm{r}}, \pi / \mathrm{p}_{\mathrm{r}}\right] \\
0 & \text { else }
\end{array}\right.
\end{gathered}
$$

The modulation process of an ideal ALR is depicted in Figures 3 and 4 for an original MMF wave with four- and two-pole pairs, respectively.
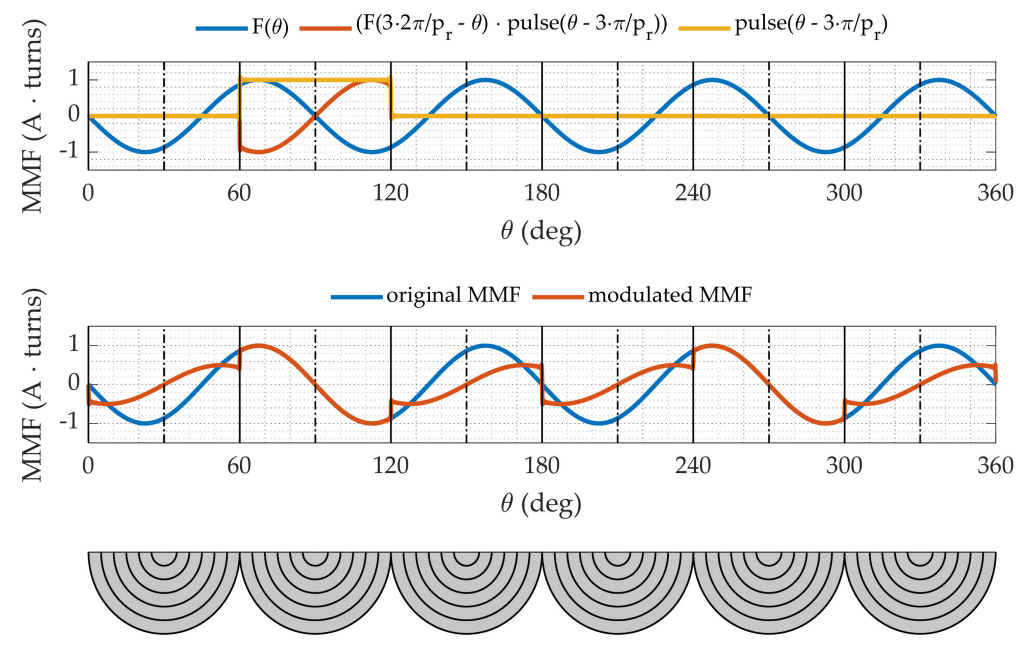

Figure 3. Effect of an ideal ALR with six rotor segments on the original MMF wave with four pole pairs. 

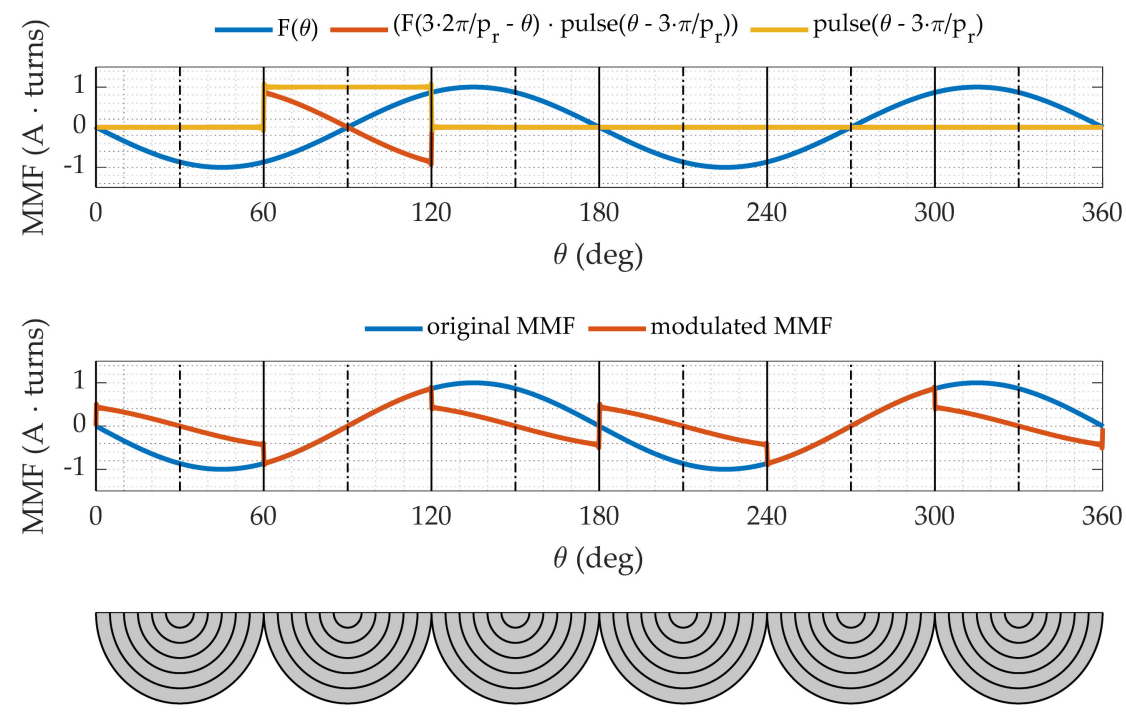

Figure 4. Effect of an ideal ALR with six rotor segments on the original MMF wave with two pole pairs.

The modulation of an original MMF wave described by Equation (7), under the influence of an ALR with $\mathrm{p}_{\mathrm{r}}$ segments, can be expressed as a Fourier series Equation (8). The details of this derivation based on Equations (5) and (6) are laid out in Appendix B.

$$
\begin{gathered}
\mathrm{F}(\theta, \mathrm{t})=\mathrm{F} \cos \left(\mathrm{p}_{\mathrm{s}} \theta-\varphi_{\mathrm{s}}(\mathrm{t})\right) \\
\mathrm{F}_{\mathrm{m}}\left(\theta, \theta_{\mathrm{r}}, \mathrm{t}\right)=\frac{\mathrm{F}}{2} \cos \left(\mathrm{p}_{\mathrm{s}} \theta-\varphi_{\mathrm{s}}(\mathrm{t})\right) \\
-\frac{\mathrm{F}}{2} \sum_{\mathrm{k}=-\infty}^{+\infty}(-1)^{\mathrm{k}} \sin \mathrm{c}\left(\frac{2 \mathrm{p}_{\mathrm{s}}+\mathrm{k} \mathrm{p}_{\mathrm{r}}}{\mathrm{p}_{\mathrm{r}}}\right) \cos \left(\left(\mathrm{p}_{\mathrm{s}}+\mathrm{kp} \mathrm{p}_{\mathrm{r}}\right) \theta-\mathrm{kp}_{\mathrm{r}} \theta_{\mathrm{r}}-\varphi_{\mathrm{s}}(\mathrm{t})\right)
\end{gathered}
$$

Expression Equation (8) shows that half of the original waveform is attenuated while the other half is modulated into spatial frequencies $\left(\mathrm{p}_{\mathrm{s}} \pm \mathrm{kp} \mathrm{p}_{\mathrm{r}}\right)$. This is illustrated in Figures 5 and 6 for a four- and two-pole pair MMF, respectively. The generation of additional spatial frequencies by the rotor lies at the base of the BDFRM working principle. Indeed, when selecting an appropriate combination of pole pairs and rotor segments Equation (1), the spatial frequency of the harmonics generated by modulation from one winding will match the spatial frequency of the original MMF of the other winding, and vice versa. This matching in spatial frequency involves a mutual coupling of the two stator windings through the rotor, which will generate net torque in steady state, on the condition that the additional time frequency condition is met Equation (2).

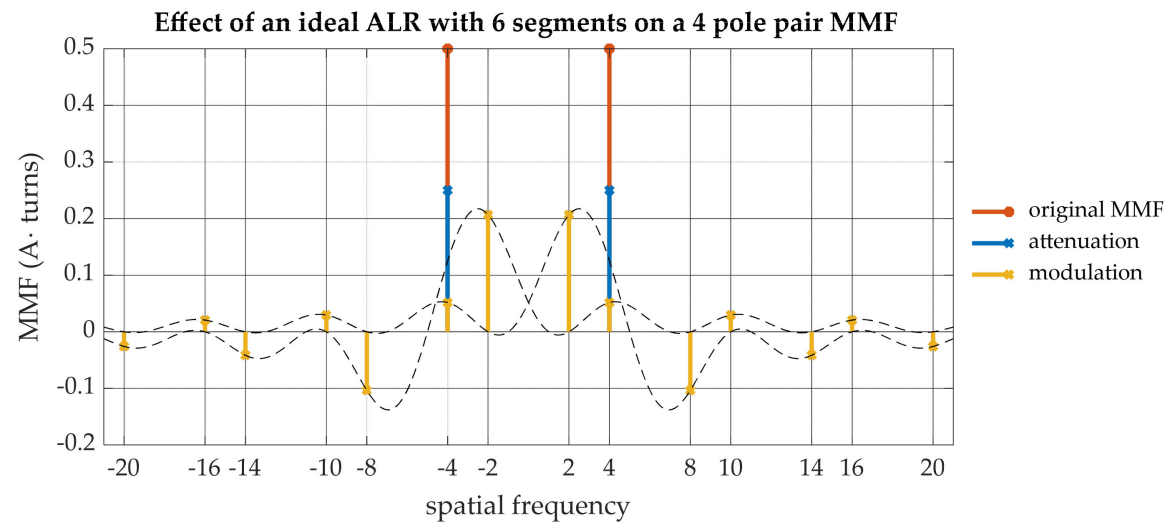

Figure 5. Spatial frequency spectrum of the original and modulated MMF waves expressed in Equation (7) for a combination: $\mathrm{p}_{\mathrm{s}}=4$ and $\mathrm{p}_{\mathrm{r}}=6$. 


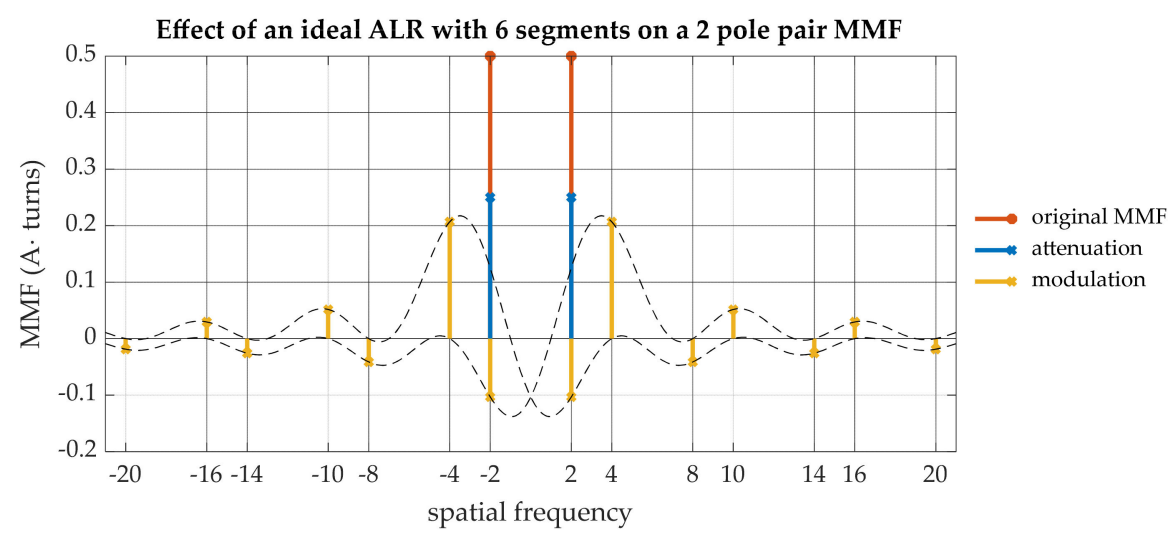

Figure 6. Spatial frequency spectrum of the original and modulated MMF waves expressed in Equation (7) for a combination: $\mathrm{p}_{\mathrm{s}}=2$ and $\mathrm{p}_{\mathrm{r}}=6$.

The Fourier coefficients of the modulated MMF wave that are relevant to the basic working principle of the ideal ALR BDFRM were called 'coupling factors' by [36]. The first appearance of such factors in the literature as 'spread factors' for an ideal segmental BDFRM can be found in [9]. The coupling factors for the grid and converter windings are defined by truncating Equation (8) to Equation (9) and Equation (10), for the case $\mathrm{p}_{\mathrm{g}}+\mathrm{p}_{\mathrm{c}}=n \mathrm{p}_{\mathrm{r}}$ with $\mathrm{n}$ a non-zero natural number. For the ideal ALR, the self-coupling and mutual factors are defined by Equation (11) and Equation (12), respectively.

$$
\begin{gathered}
\mathrm{F}_{\mathrm{mg}}\left(\theta, \theta_{\mathrm{r}}, \mathrm{t}\right)=\mathrm{F}_{\mathrm{g}} \mathrm{C}_{\mathrm{g}} \cos \left(\mathrm{p}_{\mathrm{g}} \theta-\varphi_{\mathrm{g}}(\mathrm{t})\right)+\mathrm{F}_{\mathrm{g}} \mathrm{C}_{\mathrm{gc}} \cos \left(\mathrm{p}_{\mathrm{c}} \theta-\mathrm{np}_{\mathrm{r}} \theta_{\mathrm{r}}-\varphi_{\mathrm{g}}(\mathrm{t})\right)+\ldots \text { with } \mathrm{n} \in \mathrm{N} \\
\mathrm{F}_{\mathrm{mc}}\left(\theta, \theta_{\mathrm{r}}, \mathrm{t}\right)=\mathrm{F}_{\mathrm{c}} \mathrm{C}_{\mathrm{c}} \cos \left(\mathrm{p}_{\mathrm{c}} \theta-\varphi_{\mathrm{c}}(\mathrm{t})\right)+\mathrm{F}_{\mathrm{c}} \mathrm{C}_{\mathrm{cg}} \cos \left(\mathrm{p}_{\mathrm{c}} \theta-\mathrm{np}_{\mathrm{r}} \theta_{\mathrm{r}}-\varphi_{\mathrm{c}}(\mathrm{t})\right)+\ldots \text { with } \mathrm{n} \in \mathrm{N}
\end{gathered}
$$

$$
\begin{aligned}
& C_{g}=\frac{1}{2}\left(1-\sin \mathrm{c}\left(\frac{2 \mathrm{p}_{\mathrm{g}}}{\mathrm{p}_{\mathrm{r}}}\right)\right) \quad \mathrm{C}_{\mathrm{c}}=\frac{1}{2}\left(1-\sin \mathrm{c}\left(\frac{2 \mathrm{p}_{\mathrm{c}}}{\mathrm{p}_{\mathrm{r}}}\right)\right) \\
& \mathrm{C}_{\mathrm{gc}}=\mathrm{C}_{\mathrm{cg}}=\frac{1}{2} \sin \mathrm{c}\left(\frac{2 \mathrm{p}_{\mathrm{g}}-\mathrm{n} \mathrm{p}_{\mathrm{r}}}{\mathrm{p}_{\mathrm{r}}}\right)=\frac{1}{2} \sin \mathrm{c}\left(\frac{2 \mathrm{p}_{\mathrm{c}}-\mathrm{n} \mathrm{p}_{\mathrm{r}}}{\mathrm{p}_{\mathrm{r}}}\right)
\end{aligned}
$$

\subsubsection{Ideal DSR with Single Flux Duct}

In this modeling approach, a flux guide as depicted in Figure 7 is considered, and the following assumptions are made: (i) saturation of flux guides is not considered, (ii) MMF drop inside the flux guide is not considered and (iii) magnetic flux enters and leaves the flux guides exclusively at the interface with air gap at radius $R_{r}$.

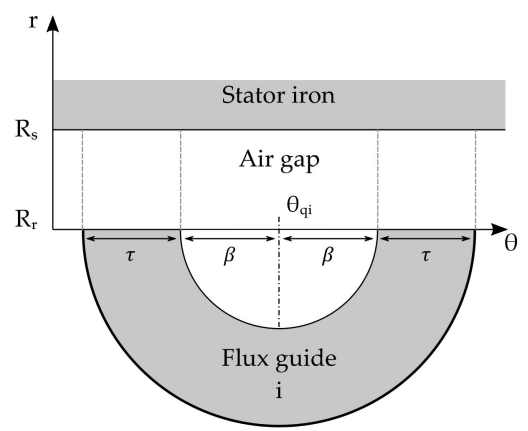

Figure 7. Model for single flux guide rotor. 
The flux entering or leaving the flux guide $i$ over the interval $\left[\theta_{1}, \theta_{2}\right]$ can be written as Equation (13), where a constant 'magnetic potential' $U_{i}$ is assumed for the flux guide.

$$
\phi=\frac{\mu_{0} L}{g}\left(R_{s} \int_{\theta_{1}}^{\theta_{2}} F_{s}(\theta) d \theta-R_{r} \int_{\theta_{1}}^{\theta_{2}} U_{i} d \theta\right)
$$

Expressing Gauss's law over the entire flux guide, where the flux over intervals $\left[\theta_{\mathrm{qi}}-\beta-\tau, \theta_{\mathrm{qi}}-\beta\right]$ and $\left[\theta_{\mathrm{qi}}+\beta, \theta_{\mathrm{qi}}+\beta+\tau\right]$ is considered, yields an expression for $\mathrm{U}_{\mathrm{i}}$ Equation (14) for an MMF wave in the shape of a pure cosine as in Equation (7).

$$
\mathrm{U}_{\mathrm{i}}\left(\theta_{\mathrm{i}}\right)=\sin \mathrm{c}\left(\frac{\mathrm{p}_{\mathrm{s}} \tau}{2 \pi}\right) \frac{\mathrm{R}_{\mathrm{s}}}{\mathrm{R}_{\mathrm{r}}} \frac{\left(\mathrm{F}_{\mathrm{s}}\left(\theta_{\mathrm{qi}}-\beta-\frac{\tau}{2}\right)+\mathrm{F}_{\mathrm{s}}\left(\theta_{\mathrm{qi}}+\beta+\frac{\tau}{2}\right)\right)}{2}
$$

By expressing the magnetic flux over the entire air gap circumference, the modulated MMF Equation (15) can be derived using a pulse function Equation (16) that will only allow non-zero flux over the intervals $\left[\theta_{\mathrm{qi}}-\beta-\tau, \theta_{\mathrm{qi}}-\beta\right]$ and $\left[\theta_{\mathrm{qi}}+\beta, \theta_{\mathrm{qi}}+\beta+\tau\right]$.

$$
\begin{gathered}
\mathrm{F}_{\mathrm{m}}\left(\theta, \theta_{\mathrm{r}}\right)=\sum_{\mathrm{i}=0}^{\mathrm{p}_{\mathrm{r}}-1}\left(\mathrm{~F}_{\mathrm{s}}(\theta)-\frac{\mathrm{R}_{\mathrm{r}}}{\mathrm{R}_{\mathrm{s}}} \mathrm{U}_{\mathrm{i}}\left(\theta_{\mathrm{qi}}\right)\right) \cdot \operatorname{pulse}\left(\theta-\theta_{\mathrm{qi}}\right) \\
\operatorname{pulse}(\theta)=\frac{\tau}{\pi}+\sum_{\mathrm{k}=1}^{+\infty} \frac{2 \tau}{\pi} \sin \mathrm{c}\left(\frac{\mathrm{k} \tau}{2 \pi}\right) \cos \left(\mathrm{k}\left(\beta+\frac{\tau}{2}\right)\right) \cos (\mathrm{k} \theta)=\left\{\begin{array}{cc}
1 & \text { if } \theta \in[-\beta-\tau,-\beta] \\
1 & \text { if } \theta \in[\beta, \beta+\tau] \\
0 & \text { else }
\end{array}\right.
\end{gathered}
$$

In contrast to the ideal ALR model, a local reference frame is considered with respect to the middle of the segment. The relation of this reference frame with the one used in the ideal ALR model is expressed by Equation (17).

$$
\theta_{\mathrm{qi}}=\theta_{\mathrm{r}}+\frac{\pi}{\mathrm{p}_{\mathrm{r}}}+\mathrm{i} \frac{2 \pi}{\mathrm{p}_{\mathrm{r}}} \mathrm{i}=0, \ldots, \mathrm{p}_{\mathrm{r}}-1
$$

The modulated MMF can finally be expressed as a Fourier series Equation (18) with coefficients Equation (19). The effect of a single flux guide segmental rotor on a four- and two-pole pair MMFs is depicted in Figures 8 and 9, respectively.

$$
\begin{gathered}
\mathrm{F}_{\mathrm{m}}\left(\theta, \theta_{\mathrm{r}}\right)=\mathrm{F} \sum_{\mathrm{k}=-\infty}^{+\infty} \mathrm{C}_{\mathrm{k}}\left(\mathrm{p}_{\mathrm{s}^{\prime}} \beta, \tau\right) \cos \left(\left(\mathrm{p}_{\mathrm{s}}+\mathrm{kp} \mathrm{p}_{\mathrm{r}}\right) \theta-\mathrm{kp}_{\mathrm{r}} \theta_{\mathrm{r}}-\varphi_{\mathrm{s}}(\mathrm{t})\right) \\
\mathrm{C}_{\mathrm{k}}\left(\mathrm{p}_{\mathrm{s}^{\prime}} \beta, \tau\right)=\frac{\tau \mathrm{p}_{\mathrm{r}}}{\pi}(-1)^{\mathrm{k}} \sin \mathrm{c}\left(\frac{\mathrm{kp}_{\mathrm{r}} \tau}{2 \pi}\right) \cos \left(\mathrm{kp}_{\mathrm{r}}\left(\beta+\frac{\tau}{2}\right)\right) \\
-\frac{\tau \mathrm{p}_{\mathrm{r}}}{\pi}(-1)^{\mathrm{k}} \sin \mathrm{c}\left(\frac{\mathrm{p}_{\mathrm{s}} \tau}{2 \pi}\right) \cos \left(\mathrm{p}_{\mathrm{s}}\left(\beta+\frac{\tau}{2}\right)\right) \sin \mathrm{c}\left(\frac{\left(\mathrm{p}_{\mathrm{s}}+\mathrm{kp}_{\mathrm{r}}\right) \tau}{2 \pi}\right) \cos \left(\left(\mathrm{p}_{\mathrm{s}}+\mathrm{k} \mathrm{p}_{\mathrm{r}}\right)\left(\beta+\frac{\tau}{2}\right)\right)
\end{gathered}
$$



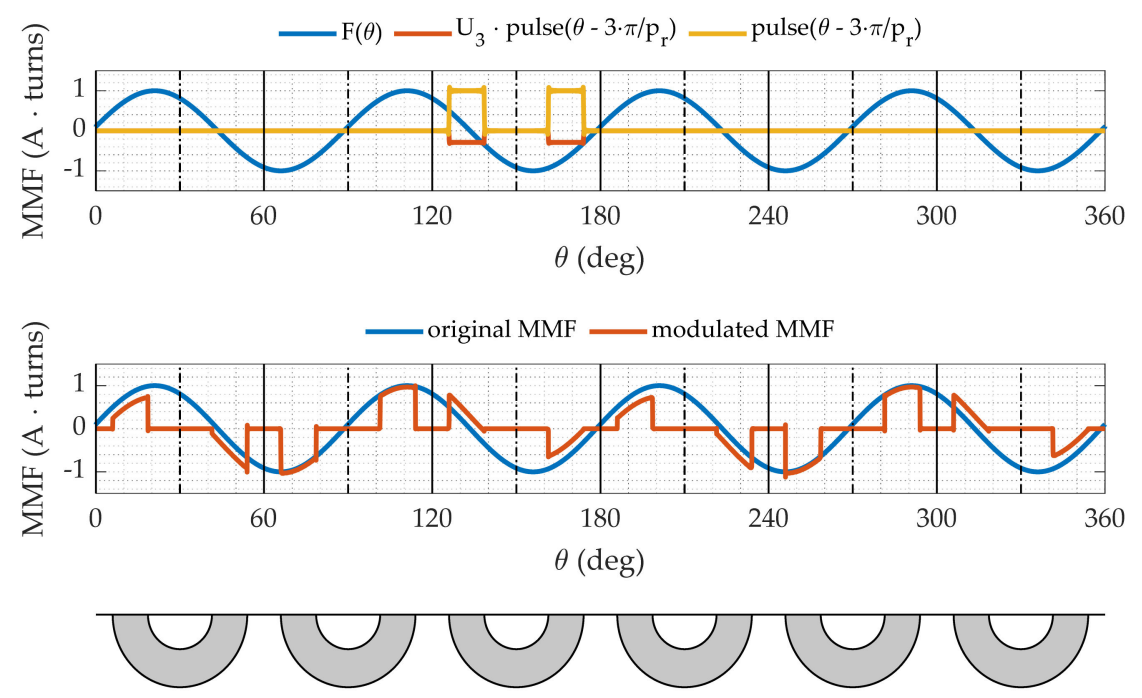

Figure 8. Effect of an ideal segmental rotor with six segments and single flux guide on the original MMF wave with four pole pairs.
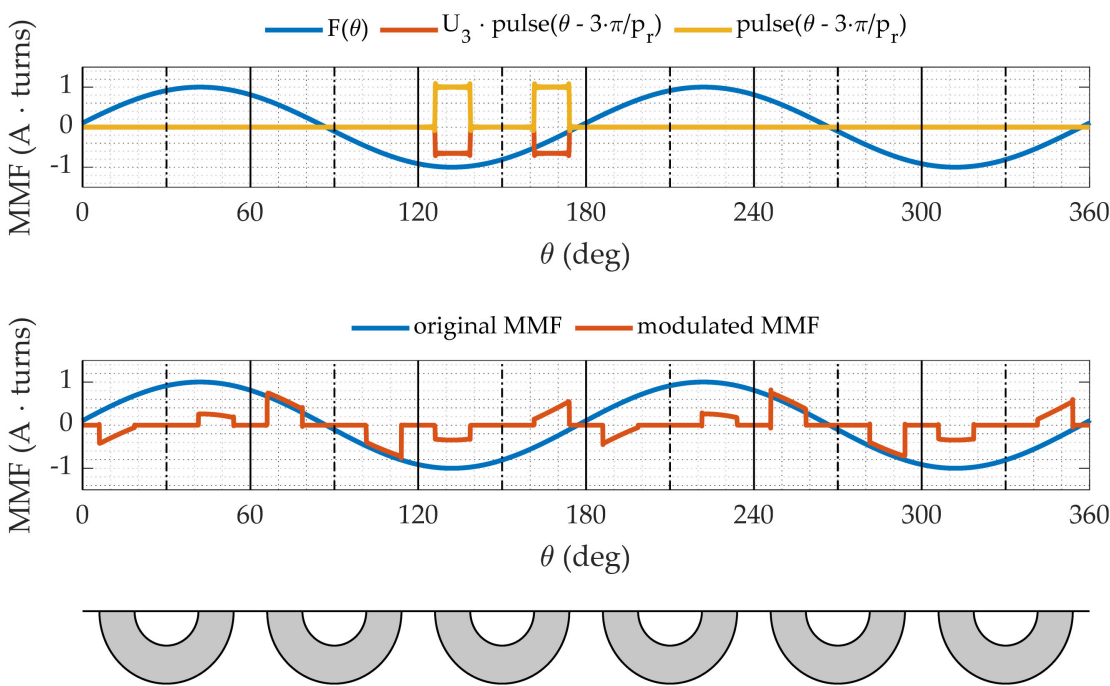

Figure 9. Effect of an ideal segmental rotor with six segments and single flux guide on the original MMF wave with two pole pairs.

The presented model does not consider the air gap share over the interval $\left[\theta_{\mathrm{qi}}-\right.$ $\left.\beta, \theta_{\mathrm{qi}}+\beta\right]$, which entails that the estimate will be the same for rotor segments with equal angles $\beta$ and $\tau$, irrespective of the air gap shape.

For a rotor meeting condition Equation (13), the new coupling factors are defined as Equations (20) and (21) for the self- and mutual-coupling, respectively, based on Equation (19).

$$
\begin{array}{cc}
C_{g}=C_{k=0}\left(p_{g}, \beta, \tau\right) & C_{c}=C_{k=0}\left(p_{c}, \beta, \tau\right) \\
C_{g c}=C_{k=-1}\left(p_{g}, \beta, \tau\right) & C_{c g}=C_{k=-1}\left(p_{c}, \beta, \tau\right)
\end{array}
$$

Compared to the ideal ALR, the spatial frequency spectra in Figures 10 and 11 show that the DSR generates more frequency components with higher amplitude, which opens the path for more potential pole-pair combinations. 


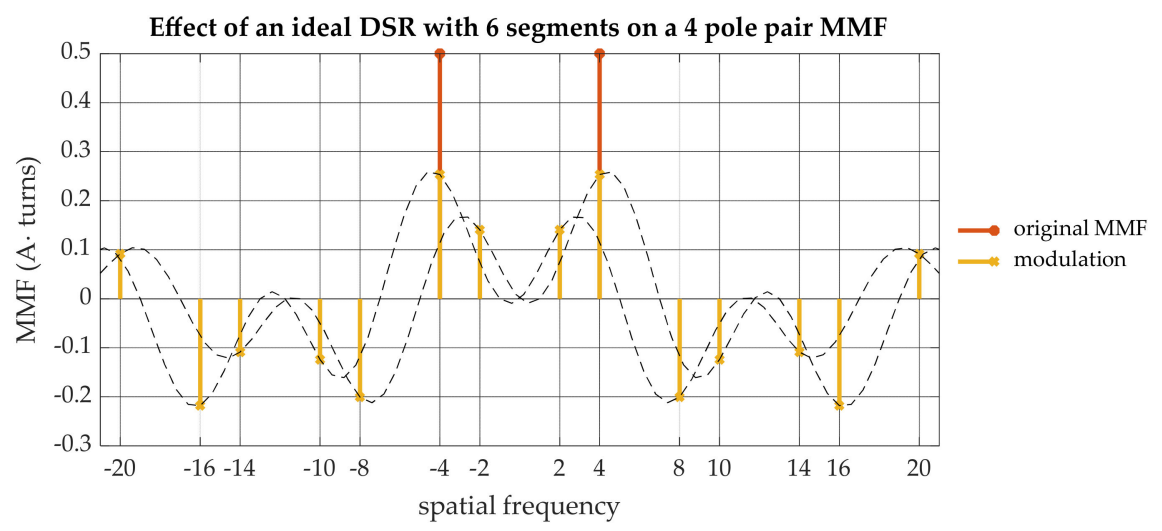

Figure 10. Spatial frequency spectrum of the original and modulated MMF waves expressed in Equation (7) for a combination: $\mathrm{p}_{\mathrm{s}}=4$ and $\mathrm{p}_{\mathrm{r}}=6$ and physical parameters $\beta=10^{\circ}$ and $\tau=10^{\circ}$.

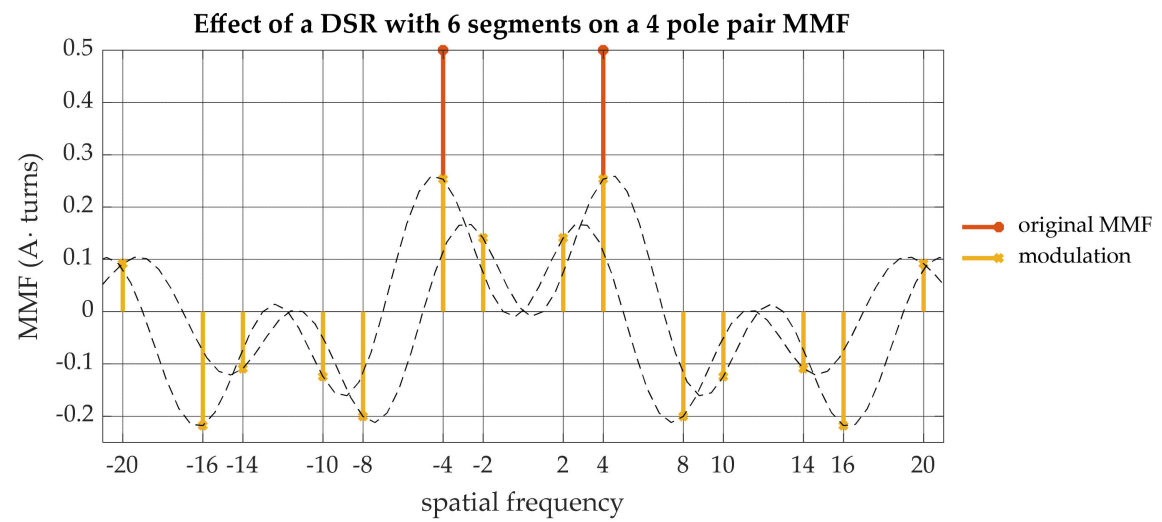

Figure 11. Spatial frequency spectrum of the original and modulated MMF waves expressed in Equation (7) for a combination: $\mathrm{p}_{\mathrm{s}}=2$ and $\mathrm{p}_{\mathrm{r}}=6$ and physical parameters $\beta=10^{\circ}$ and $\tau=10^{\circ}$.

\subsubsection{Salient Pole Rotor}

The modulation process of the SPR can be divided in two parts Equation (22). First, the effect of the rotor poles, the parts of the rotor with the smallest air gap, will be modeled using a pulse function that is one at the rotor poles and zero at the rotor slots Equation (23). An ideal SPR would be modeled by only considering the rotor poles. Modeling the effect of the rotor slots involves adding a similar pulse function Equation (24) but with an attenuation Equation (25) that is derived from the static solution of Ampere's law for a round rotor with rotor slot radius $R_{\text {slot, }}$ as detailed in $[38,39]$. The only part that is not considered here is thus the transition between rotor slots and rotor poles. Therefore, the analytical model that is presented will give a slight underestimation of the radial flux density.

$$
\begin{aligned}
& \mathrm{F}_{\mathrm{m}}\left(\theta, \theta_{\mathrm{r}}\right)=\left(\text { pulse }_{\text {poles }}\left(\theta-\theta_{\mathrm{r}}\right)+\rho_{\text {slots }} \text { pulse }_{\text {slots }}\left(\theta-\theta_{\mathrm{r}}\right)\right) \cdot \mathrm{F}(\theta) \\
& \text { pulse }_{\text {poles }}(\theta)=\frac{\tau \mathrm{p}_{\mathrm{r}}}{\pi}+\sum_{\mathrm{k}=1}^{\infty} \frac{4}{\mathrm{k} \pi} \sin \left(\mathrm{kp}_{\mathrm{r}} \frac{\tau}{2}\right) \cos \left(\mathrm{kp}_{\mathrm{r}} \frac{\tau}{2}\right) \cos \left(\mathrm{kp}_{\mathrm{r}} \theta\right) \\
& \text { pulse }_{\text {slots }}(\theta)=\rho_{\text {slots }}\left(\frac{\beta p_{\mathrm{r}}}{\pi}+\sum_{\mathrm{k}=1}^{\infty}(-1)^{\mathrm{k}} \frac{2}{\mathrm{k} \pi} \sin \left(\mathrm{kp}_{\mathrm{r}} \beta\right) \cos \left(k \mathrm{p}_{\mathrm{r}} \theta\right)\right) \\
& \rho_{\text {slots }}=\frac{g p_{s}}{R_{m}} \frac{\left(\frac{R_{m}}{R_{\text {slot }}}\right)^{p_{s}}+\left(\frac{R_{\text {slot }}}{R_{m}}\right)^{p_{s}}}{\left(\frac{R_{s}}{R_{\text {slot }}}\right)^{p_{s}}-\left(\frac{R_{\text {slot }}}{R_{s}}\right)^{p_{s}}}
\end{aligned}
$$


The waveforms in a BDFRM with an SPR are illustrated in Figures 12 and 13 for a four- and two-pole pair excitation, respectively.

$$
\begin{gathered}
\mathrm{F}_{\mathrm{m}}\left(\theta, \theta_{\mathrm{r}}\right)=\frac{\mathrm{Fp}_{\mathrm{r}}}{\pi} . \\
\sum_{\mathrm{k}=-\infty}^{+\infty}\left(\tau \sin \mathrm{c}\left(\frac{\mathrm{kp}_{\mathrm{r}} \tau}{\pi}\right)+(-1)^{\mathrm{k}} \rho_{\text {slots }} \beta \sin \mathrm{c}\left(\frac{\mathrm{kp}_{\mathrm{r}} \beta}{\pi}\right)\right) \cos \left(\left(\mathrm{p}_{\mathrm{s}}+\mathrm{kp}_{\mathrm{r}}\right) \theta-\mathrm{kp}_{\mathrm{r}} \theta_{\mathrm{r}}-\varphi_{\mathrm{s}}\right)
\end{gathered}
$$
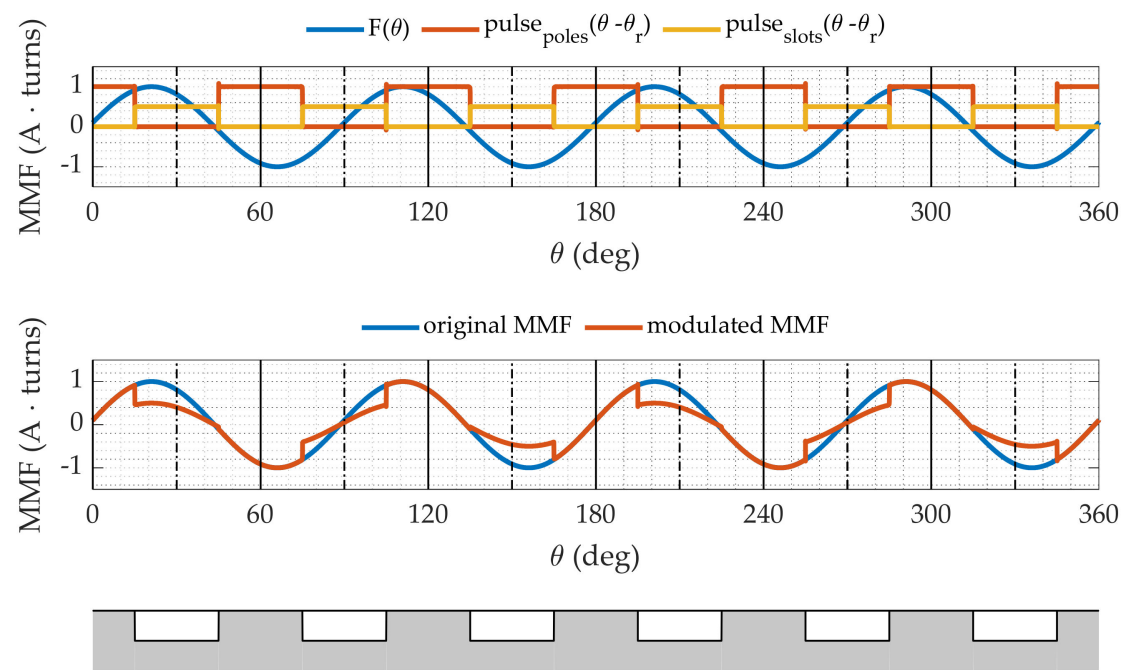

Figure 12. Effect of salient pole rotor with six poles on the original MMF wave with four pole pairs.
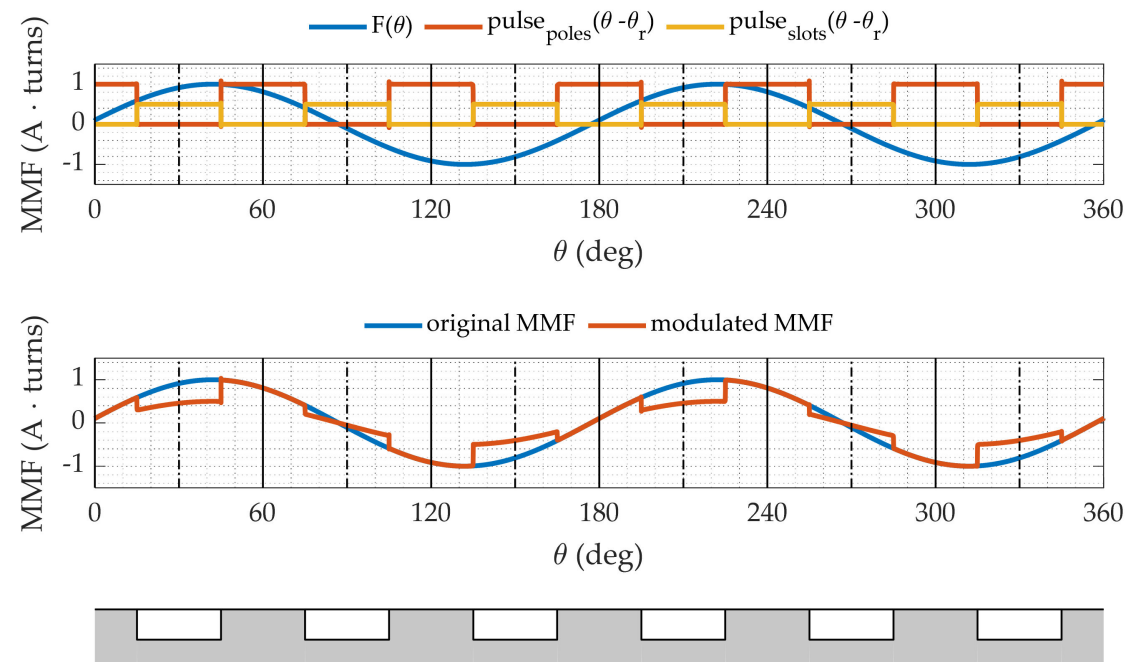

Figure 13. Effect of salient pole rotor with six poles on the original MMF wave with two pairs.

The modulated MMF wave Equation (26) is found to have a similar Fourier series as the ideal ALR rotor except for the Fourier coefficients. The grid and control winding coupling factors for the SPR are defined as Equations (27) and (28).

$$
\begin{gathered}
C_{g}=\frac{p_{r}}{\pi}\left(\tau+\rho_{\text {slots }} \beta\right) \quad C_{c}=\frac{p_{r}}{\pi}\left(\tau+\rho_{\text {slots }} \beta\right) \\
C_{g c}=C_{c g}=\frac{p_{r}}{\pi}\left(\tau \operatorname{sinc}\left(\frac{p_{r} \tau}{\pi}\right)-\rho_{\text {slots }} \beta \sin \mathrm{c}\left(\frac{p_{r} \beta}{\pi}\right)\right)
\end{gathered}
$$




\subsubsection{Phase Inductances}

Based on the analysis in the previous sections, the effect of the different rotors on the original MMF wave of phase $i$ of stator winding $x \in\{c, g\}$ can be written as Equation (29) where coefficients $C_{\mathrm{x}, \mathrm{k}}$ are dependent on the rotor type, and physical parameters. The phase shift $\phi_{\mathrm{i}}$ and $\phi_{\mathrm{j}}$ are limited to the set $\left\{-\frac{2 \pi}{3}, 0,+\frac{2 \pi}{3}\right\}$, where $\mathrm{i}, \mathrm{j} \in\{\mathrm{u}, \mathrm{v}, \mathrm{w}\}$ for a three-phase winding. The phases $\phi_{\mathrm{g}}$ and $\phi_{\mathrm{c}}$ represent the position of the magnetic axis of phase $\mathrm{u}$ of the grid and control winding, respectively.

$$
\mathrm{F}_{\mathrm{mx}, \mathrm{i}}\left(\theta, \theta_{\mathrm{r}}, \mathrm{t}\right)=\mathrm{F}_{\mathrm{x}, \mathrm{i}} \sum_{\mathrm{k}=-\infty}^{+\infty} \mathrm{C}_{\mathrm{x}, \mathrm{k}} \cos \left(\left(\mathrm{p}_{\mathrm{x}}+\mathrm{k} \mathrm{p}_{\mathrm{r}}\right) \theta-\mathrm{kp}_{\mathrm{r}} \theta_{\mathrm{r}}-\phi_{\mathrm{x}}-\phi_{\mathrm{i}}\right)
$$

Using the fundamental component of the winding function $\mathrm{N}_{\mathrm{y}, \mathrm{i}}(\theta)$ with $\mathrm{y} \in\{\mathrm{c}, \mathrm{g}\}$, the phase inductances for the grid and control winding are derived in Equation (31) and Equation (32), respectively, as well as the mutual inductances between the two stator windings Equation (33). The latter is showing a rotor position dependency, expressing the reluctance nature of the BDFRM. These expressions are derived for the case of Equation (30) of Equation (1).

$$
\begin{gathered}
\mathrm{p}_{\mathrm{r}}=\mathrm{p}_{\mathrm{g}}+\mathrm{p}_{\mathrm{c}} \\
\mathrm{L}_{\mathrm{jc}, \mathrm{ic}}=\frac{\mu_{0} \pi \mathrm{R}_{\mathrm{s}} \mathrm{L}}{\mathrm{g}}\left(\frac{4}{\pi} \frac{\mathrm{k}_{\mathrm{w}, \mathrm{c}} \mathrm{N}_{\mathrm{c}}}{2 \mathrm{p}_{\mathrm{c}}}\right)^{2} \mathrm{C}_{\mathrm{c}} \cos \left(\phi_{\mathrm{j}}-\phi_{\mathrm{i}}\right) \\
\mathrm{L}_{\mathrm{jg}, \mathrm{ig}}=\frac{\mu_{0} \pi \mathrm{R}_{\mathrm{s}} \mathrm{L}}{\mathrm{g}}\left(\frac{4}{\pi} \frac{\mathrm{k}_{\mathrm{w}, \mathrm{g} \mathrm{N}_{\mathrm{g}}}}{2 \mathrm{p}_{\mathrm{g}}}\right)^{2} \mathrm{C}_{\mathrm{g}} \cos \left(\phi_{\mathrm{j}}-\phi_{\mathrm{i}}\right) \\
\mathrm{M}_{\mathrm{j} g, \mathrm{ic}}=\frac{\mu_{0} \pi \mathrm{R}_{\mathrm{s}} \mathrm{L}}{\mathrm{g}}\left(\frac{4}{\pi} \frac{\mathrm{k}_{\mathrm{w}, \mathrm{g} \mathrm{N}_{\mathrm{g}}}}{2 \mathrm{p}_{\mathrm{g}}}\right)\left(\frac{4}{\pi} \frac{\mathrm{k}_{\mathrm{w}, \mathrm{c}} \mathrm{N}_{\mathrm{c}}}{2 \mathrm{p}_{\mathrm{c}}}\right) \mathrm{C}_{\mathrm{gc}} \cos \left(\mathrm{p}_{\mathrm{r}} \theta_{\mathrm{r}}-\phi_{\mathrm{j}}-\phi_{\mathrm{i}}-\phi_{\mathrm{g}}-\phi_{\mathrm{c}}\right)
\end{gathered}
$$

\subsection{Time Frequency Analysis}

The modulation process by the reluctance rotor not only affects the field distribution in space, i.e., along the circumference of the air gap, but also in time. This is due to the reluctance nature of the BDFRM, which will generate torque in order to place the magnetically anisotropic rotor in a position of minimum coenergy, as demonstrated by [40].

With the assumption of linear magnetic behavior, based on Equation (8), and in the case of a sum in Equation (33), the coenergy for a purely cosine MMF distribution can be derived Equation (34), as presented in Appendix C.

$$
\begin{gathered}
\mathrm{W}\left(\theta_{\mathrm{r}}, \mathrm{t}\right)=\frac{\mu_{0}}{\mathrm{~g}} \frac{\pi \mathrm{R}_{\mathrm{s}} \mathrm{L}}{2}\left(\mathrm{~F}_{\mathrm{g}}^{2} \sum_{\mathrm{k}=-\infty}^{+\infty} \mathrm{C}_{\mathrm{gk}}^{2}+\mathrm{F}_{\mathrm{c}}^{2} \sum_{\mathrm{k}=-\infty}^{+\infty} \mathrm{C}_{\mathrm{ck}}^{2}\right) \\
+\frac{\mu_{0}}{\mathrm{~g}} \frac{\pi \mathrm{R}_{\mathrm{s}} \mathrm{L}}{2}\left(2 \mathrm{~F}_{\mathrm{g}} \mathrm{F}_{\mathrm{c}}\left(\frac{\mathrm{C}_{\mathrm{gc}}+\mathrm{C}_{\mathrm{cg}}}{2}\right) \cos \left(\mathrm{p}_{\mathrm{r}} \theta_{\mathrm{r}}-\varphi_{\mathrm{g}}(\mathrm{t})-\varphi_{\mathrm{c}}(\mathrm{t})\right)\right)
\end{gathered}
$$

The reluctance torque developed by the BDFRM in Equation (35) is found to be dependent on the product of the MMF amplitudes and the relative rotor position with respect to the grid and control MMF waves.

$$
\begin{gathered}
\mathrm{T}(\mathrm{t})=\frac{\partial \mathrm{W}\left(\theta_{\mathrm{r}, \mathrm{t}}\right)}{\partial \theta_{\mathrm{r}}} \\
=-\frac{\mu_{0}}{\mathrm{~g}} \frac{\pi \mathrm{R}_{\mathrm{s}} \mathrm{L}}{2} \mathrm{p}_{\mathrm{r}} \mathrm{F}_{\mathrm{g}} \mathrm{F}_{\mathrm{c}}\left(\mathrm{C}_{\mathrm{gc}}+\mathrm{C}_{\mathrm{cg}}\right) \sin \left(\mathrm{p}_{\mathrm{r}} \theta_{\mathrm{r}}-\varphi_{\mathrm{g}}(\mathrm{t})-\varphi_{\mathrm{c}}(\mathrm{t})\right)
\end{gathered}
$$

During normal operation of the machine, the MMF waves are rotating with angular velocities $\omega_{\mathrm{g}}$ and $\omega_{\mathrm{c}}$ and phase shifts $\phi_{\mathrm{g}}$ and $\phi_{\mathrm{c}}$ with respect to an arbitrary reference, as in Equations (36) and (37) for the grid and control winding, respectively. The rotor position will depend on angular velocity $\Omega_{\mathrm{r}}$ and phase shift $\gamma$ with respect to that same 
reference Equation (38). This phase shift is commonly denominated as the load angle in mechanical radians.

$$
\begin{aligned}
\varphi_{\mathrm{g}}(\mathrm{t}) & =\omega_{\mathrm{g}} \mathrm{t}+\phi_{\mathrm{g}} \\
\varphi_{\mathrm{c}}(\mathrm{t}) & =\omega_{\mathrm{c}} \mathrm{t}+\phi_{\mathrm{c}} \\
\theta_{\mathrm{r}}(\mathrm{t}) & =\Omega_{\mathrm{r}} \mathrm{t}+\gamma
\end{aligned}
$$

For the BDFRM to generate a constant reluctance torque in steady state, the time frequency condition Equation (39) must be met. In that case, the amplitude of torque is given by Equation (40).

$$
\begin{gathered}
\Omega_{\mathrm{r}}=\frac{\omega_{\mathrm{g}}+\omega_{\mathrm{c}}}{\mathrm{p}_{\mathrm{r}}} \\
\mathrm{T}=-\frac{\mu_{0}}{\mathrm{~g}} \frac{\pi \mathrm{R}_{\mathrm{s}} \mathrm{L}}{2} \mathrm{p}_{\mathrm{r}} \mathrm{F}_{\mathrm{g}} \mathrm{F}_{\mathrm{c}}\left(\mathrm{C}_{\mathrm{gc}}+\mathrm{C}_{\mathrm{cg}}\right) \sin \left(\mathrm{p}_{\mathrm{r}} \gamma-\phi_{\mathrm{g}}-\phi_{\mathrm{c}}\right)
\end{gathered}
$$

Finally, rewriting the expression for electromagnetic torque Equation (40) in terms of RMS linear current density of the grid and control windings $\mathrm{K}_{\mathrm{sg}}$ and $\mathrm{K}_{\mathrm{sc}}$ in $\mathrm{A} / \mathrm{m}$, defined in terms of RMS current by Equation (41) with $x \in\{c, g\}$, respectively, yields the sizing equation for the BDFRM Equation (42).

$$
\begin{gathered}
\mathrm{K}_{\mathrm{sx}}=\frac{3}{\pi} \frac{\mathrm{k}_{\mathrm{w}, \mathrm{x}} \mathrm{N}_{\mathrm{x}}}{\mathrm{R}_{\mathrm{s}}} \mathrm{I}_{\mathrm{x}} \\
\mathrm{T}=-2 \frac{\mu_{0} \pi \mathrm{R}_{\mathrm{s}}^{3} \mathrm{~L}}{\mathrm{~g}}\left(\frac{\mathrm{C}_{\mathrm{gc}}+\mathrm{C}_{\mathrm{cg}}}{2}\right) \frac{\mathrm{p}_{\mathrm{r}}}{\mathrm{p}_{\mathrm{g}} \mathrm{p}_{\mathrm{c}}}\left(\mathrm{K}_{\mathrm{sg}} \mathrm{K}_{\mathrm{sc}}\right) \sin \left(\mathrm{p}_{\mathrm{r}} \theta_{\mathrm{r}}-\varphi_{\mathrm{g}}(\mathrm{t})-\varphi_{\mathrm{c}}(\mathrm{t})\right)
\end{gathered}
$$

\section{Results}

\subsection{Verification with FEA}

\subsubsection{Salient Pole Rotor}

Finally, the proposed model is verified with FEA for an SPR and an approximation of an ideal stator where the stator is modeled as a current sheet of finite thickness. An FFT analysis on the field value in the middle of the air gap allows the retrieval of the coupling coefficients, presented in Table 1. A relatively high accuracy is reached for the proposed model of the SPR which is mainly due to the modeling of the flux through the rotor slots. The remaining discrepancy is due to the flux going through the radial sides of the rotor poles, which also explains why the proposed model gives a slight underestimation. The waveforms also show a good match in Figure 14.

Table 1. Accuracy of the proposed model in relation to the FEA solution for an SPR with six rotor poles.

\begin{tabular}{cccccccccc}
\hline & $\mathrm{C}_{\mathrm{g}}$ & $\boldsymbol{\Delta}_{\mathbf{r}}(\mathbf{\%})^{\mathbf{1}}$ & $\mathrm{C}_{\mathrm{gc}}$ & $\boldsymbol{\Delta}_{\mathrm{r}} \mathbf{( \% )} \mathbf{1}^{\mathbf{1}}$ & $\mathrm{C}_{\mathrm{c}}$ & $\boldsymbol{\Delta}_{\mathbf{r}}(\mathbf{\%})^{\mathbf{1}}$ & $\mathrm{C}_{\mathrm{cg}}$ & $\boldsymbol{\Delta}_{\mathrm{r}}(\mathbf{\%}) \mathbf{1}^{\mathbf{1}}$ \\
\hline FEA & 0.3887 & - & 0.2715 & - & 0.3932 & - & 0.2724 & - \\
Proposed model & 0.3637 & -6.4 & 0.2631 & -3 & 0.3676 & -6.5 & 0.2614 & -4 \\
\hline
\end{tabular}

\footnotetext{
${ }^{1}$ Relative error in relation to the FEA results.
} 


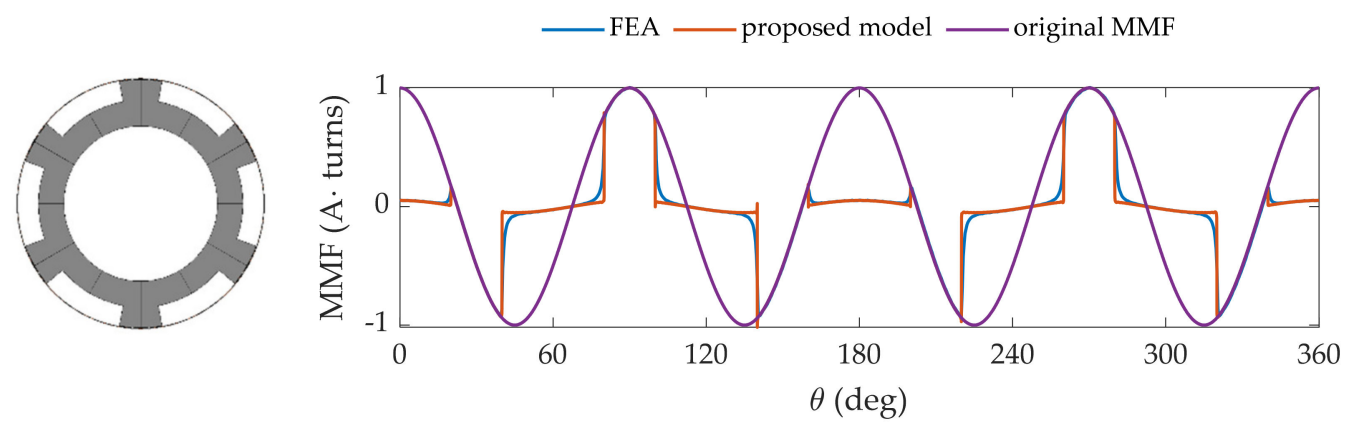

(a)

(b)

Figure 14. (a) FEA model for an SPR. (b) Waveform comparison of the modulated MMF of the proposed model for a DSR with the FEM solution, for a stator excitation with four pole pairs.

\subsubsection{Ducted Segmental Rotor}

The waveform of the proposed model is closer to the FEA result than the ideal ALR model, as illustrated in Figure 15. Furthermore, the improvement brought by the proposed model is quantified in Table 2, where the inaccuracy of the mutual coupling coefficient is reduced by more than $70 \%$. The self-coupling factors are also improved. The relatively high error on the self-coupling factors is due to the absence of leakage in the proposed model. Finally, the proposed model gives an underestimation of the mutual coupling coefficient because some flux lines that are not modeled are contributing to the mutual coupling of the two stator windings. Flux lines that are not captured in the proposed model are illustrated in Figure 16.

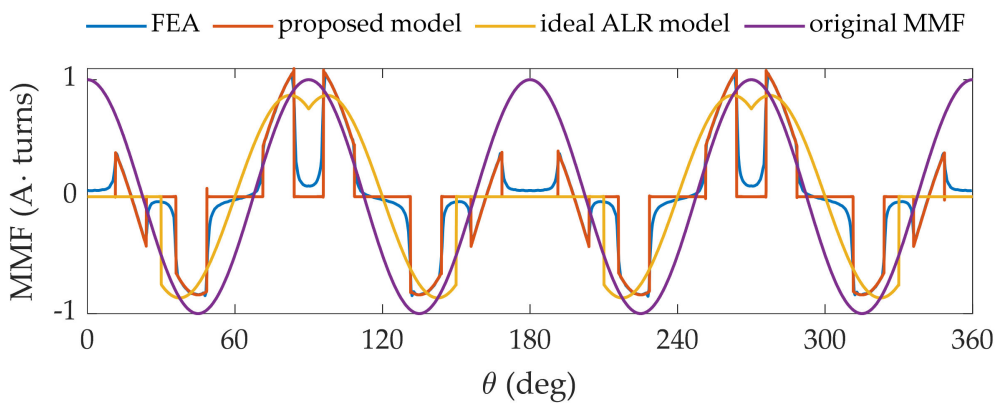

Figure 15. Waveform comparison of the modulated MMF of the proposed for a DSR and the ideal ALR model with the solution obtained with FEA for a DSR with the FEM solution, for a stator excitation with four pole pairs.

Table 2. Accuracy improvement of the presented model for a DSR with respect to the ideal ALR model.

\begin{tabular}{|c|c|c|c|c|c|c|c|c|}
\hline & $\mathrm{C}_{\mathrm{g}}$ & $\Delta_{\mathrm{r}}(\%)^{1}$ & $\mathrm{C}_{\mathrm{gc}}$ & $\Delta_{\mathrm{r}}(\%)^{1}$ & $\mathrm{C}_{\mathrm{c}}$ & $\Delta_{\mathrm{r}}(\%)^{1}$ & $\mathrm{C}_{\mathrm{cg}}$ & $\Delta_{\mathrm{r}}(\%)^{1}$ \\
\hline FEA & 0.1953 & - & 0.2329 & - & 0.4552 & - & 0.2326 & - \\
\hline $\begin{array}{c}\text { Ideal ALR } \\
\text { model }\end{array}$ & 0.2933 & +50 & 0.4135 & +78 & 0.6034 & +33 & 0.4135 & +78 \\
\hline $\begin{array}{c}\text { Proposed } \\
\text { model }\end{array}$ & 0.1430 & -27 & 0.2177 & -7 & 0.3765 & -17 & 0.2177 & -6 \\
\hline
\end{tabular}

\footnotetext{
${ }^{1}$ Relative error in relation to the FEA results.
} 


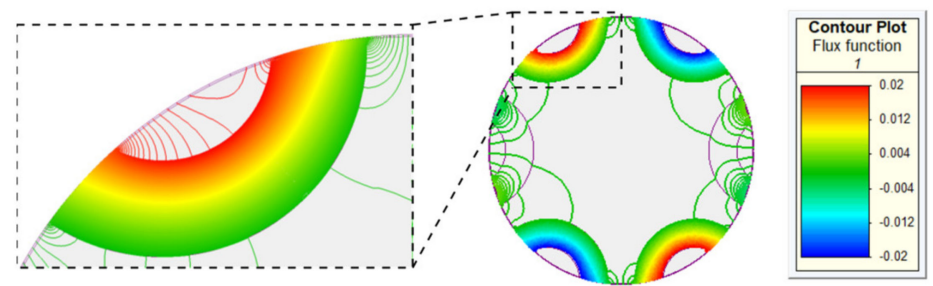

Figure 16. FEA solution for a DSR with ideal stator excitation with four-pole pairs. The color legend expresses magnetic flux in $W b$. One segment is magnified to illustrate flux lines that are not included in the proposed model.

\subsubsection{Sensitivity Analysis for DSR}

As leakage and non-modeled flux paths change with the geometry of the rotor, so does the accuracy of the proposed model. Figure 17 shows how the mutual coupling coefficient changes in function of angle $\beta$ while $\tau$ is kept constant at $10^{\circ}$. Aside from the two extrema, i.e., $\beta$ equal to $0^{\circ}$ and $20^{\circ}$, which coincide with a purely segmental rotor and a salient pole rotor, respectively, the error of the proposed model stays within $10 \%$ compared to FEA.

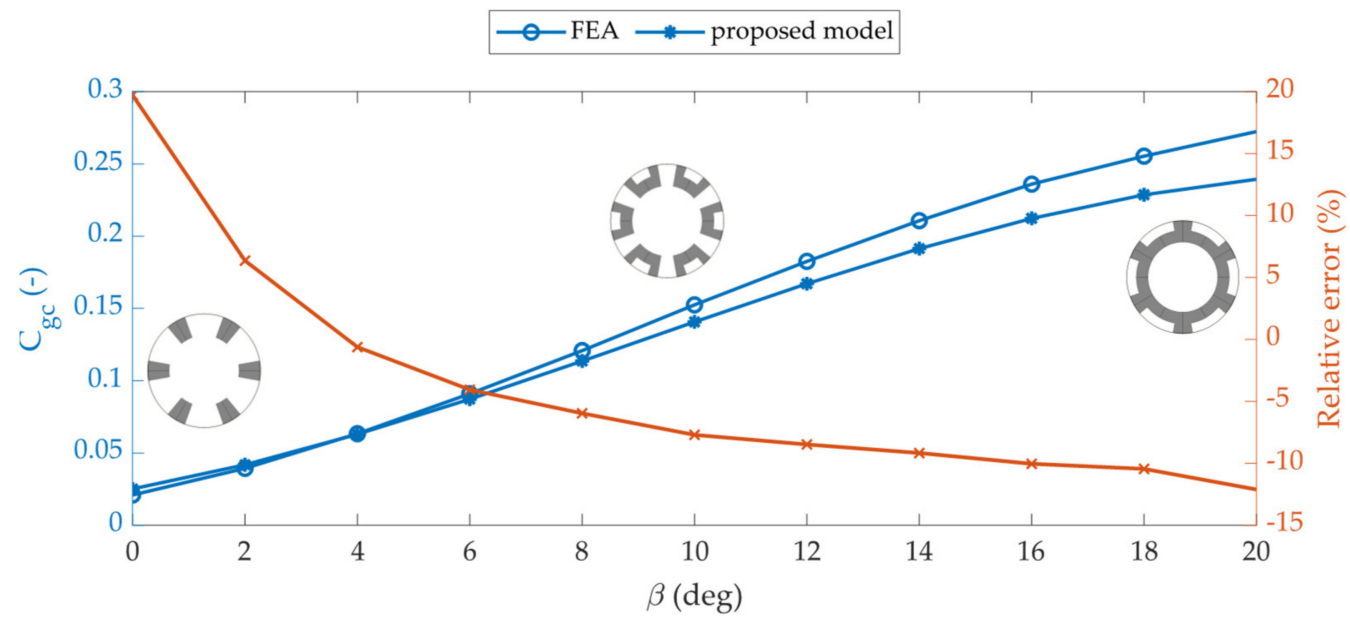

Figure 17. Effect on the mutual coupling factor with variation in angle $\beta$ for a fixed angle $\tau=10^{\circ}$.

\subsubsection{DSR with Multiple Flux Ducts}

Considering the assumptions of the proposed model for a DSR with single flux duct, expression Equation (18) can be extended to a total Fourier coefficient $C_{n}$, total for a rotor segment with $\mathrm{N}_{\mathrm{D}}$ flux guides by adding up the coefficients of the different flux guides Equation (43).

$$
C_{n, \text { total }}=\sum_{i=1}^{N_{D}} C_{n}\left(\beta_{i}, \tau_{i}\right)
$$

This is verified with FEA for a rotor with three and four flux ducts as illustrated in Figure 18a,b, respectively. The results in Tables 3 and 4 show that on the one side, the proposed model still manages to estimate the mutual coupling factors with $18 \%$ relative error. The FEA results also show that the accuracy of ideal ALR model for the self-coupling factors depends on the amount and position of the flux ducts. When $\beta_{i}$ and $\tau_{i}$ are such that the distance between neighboring segments is small, the ALR model gives a better estimate for the self-coupling factors than the proposed model. The waveforms in Figure 18c, d also show that the peaks of the FEA solution are close to the ideal ALR model for the rotor with a higher number of flux ducts and with close distance between segments. For DSRs with a geometry that is close to Figure $18 \mathrm{c}$ a combination of the ideal ALR model for the self-coupling factors and the proposed model for the mutual coupling factors. 


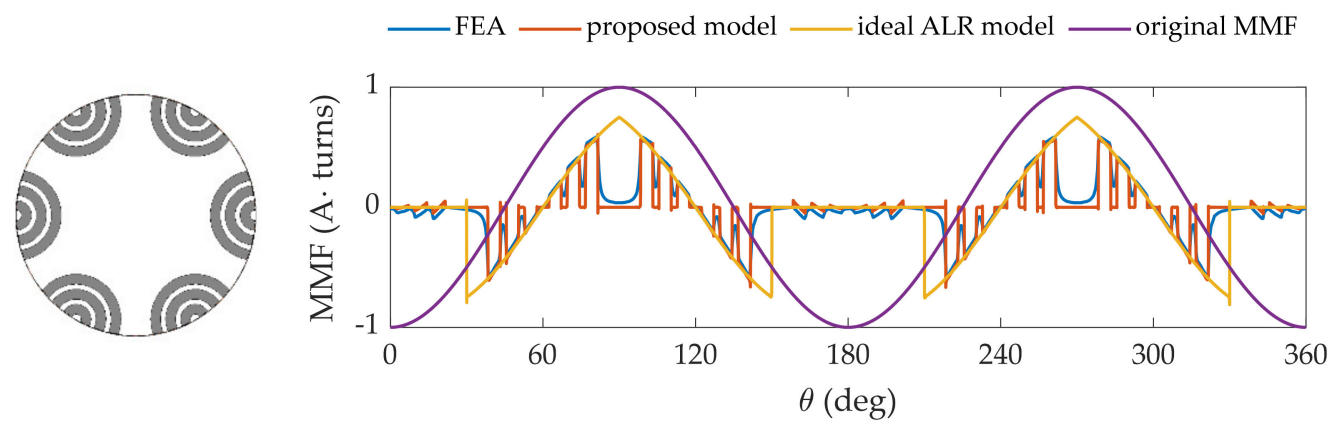

(a)

(c)
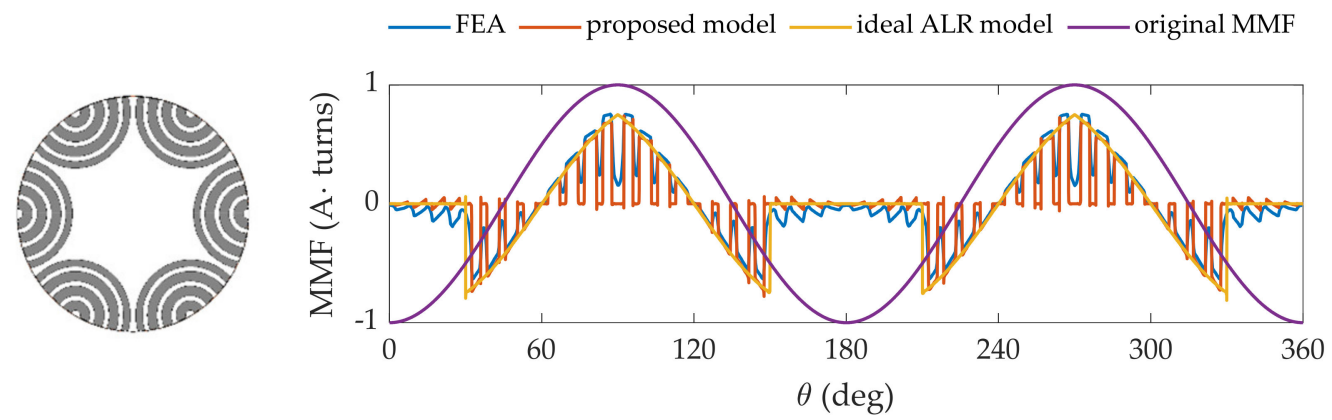

(b)

(d)

Figure 18. $(\mathbf{a}, \mathbf{b})$ are FEA models for a segmental rotor with three and four flux guides, respectively. (c,d) are waveform comparisons of the modulated MMF of the proposed and the ideal ALR model with the FEM solution with a stator with four pole pairs for a segmental rotor with three and four flux guides, respectively.

Table 3. Accuracy improvement of the presented model for a DSR with three flux ducts in relation to the ideal ALR model.

\begin{tabular}{ccccccccc}
\hline & $\mathrm{C}_{\mathrm{g}}$ & $\boldsymbol{\Delta}_{\mathrm{r}}(\mathbf{\%})^{\mathbf{1}}$ & $\mathrm{C}_{\mathrm{gc}}$ & $\boldsymbol{\Delta}_{\mathrm{r}}(\mathbf{\%})^{\mathbf{1}}$ & $\mathrm{C}_{\mathrm{c}}$ & $\boldsymbol{\Delta}_{\mathrm{r}}(\mathbf{\%})^{\mathbf{1}}$ & $\mathrm{C}_{\mathrm{cg}}$ & $\boldsymbol{\Delta}_{\mathrm{r}}(\mathbf{\%})^{\mathbf{1}}$ \\
\hline $\begin{array}{c}\text { FEA } \\
\text { Ideal }\end{array}$ & 0.1537 & - & 0.1871 & - & 0.3765 & - & 0.1883 & - \\
$\begin{array}{c}\text { ALR } \\
\text { model }\end{array}$ & 0.2933 & +91 & 0.4135 & +121 & 0.6034 & +60 & 0.4135 & +120 \\
$\begin{array}{c}\text { Proposed } \\
\text { model }\end{array}$ & 0.0938 & -39 & 0.1540 & -18 & 0.2600 & -31 & 0.1539 & -18 \\
\hline
\end{tabular}

${ }^{1}$ Relative error in relation to the FEA results.

Table 4. Accuracy improvement of the presented model for a DSR with four flux ducts in relation to the ideal ALR model.

\begin{tabular}{ccccccccc}
\hline & $\mathrm{C}_{\mathrm{g}}$ & $\boldsymbol{\Delta}_{\mathrm{r}}(\mathbf{\%})^{\mathbf{1}}$ & $\mathrm{C}_{\mathrm{gc}}$ & $\boldsymbol{\Delta}_{\mathrm{r}}(\mathbf{\%})^{\mathbf{1}}$ & $\mathrm{C}_{\mathrm{c}}$ & $\boldsymbol{\Delta}_{\mathrm{r}}(\mathbf{\%})^{\mathbf{1}}$ & $\mathrm{C}_{\mathrm{cg}}$ & $\boldsymbol{\Delta}_{\mathrm{r}}(\mathbf{\%})^{\mathbf{1}}$ \\
\hline $\begin{array}{c}\text { FEA } \\
\text { Ideal }\end{array}$ & 0.2719 & - & 0.2974 & - & 0.5249 & - & 0.2968 & - \\
$\begin{array}{c}\text { ALR } \\
\text { model }\end{array}$ & 0.2933 & +8 & 0.4135 & +39 & 0.6034 & +15 & 0.4135 & +39 \\
$\begin{array}{c}\text { Proposed } \\
\text { model }\end{array}$ & 0.1670 & -39 & 0.2442 & -18 & 0.3727 & -29 & 0.2441 & -18 \\
\hline
\end{tabular}

${ }^{1}$ Relative error in relation to the FEA results.

\subsection{Experimental Results}

The proposed model for the mutual coupling factor is validated on a BDFRM prototype depicted in Figure 19, for which the specifications are presented in Table 5. The rotor is of DSR type with a single flux duct. 


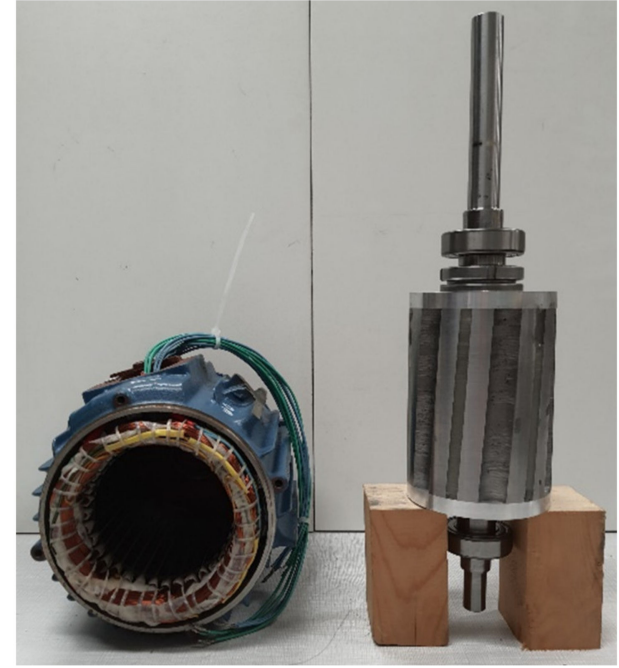

(a)

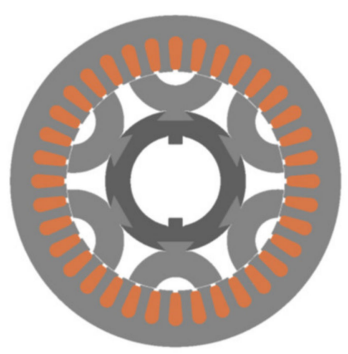

(b)

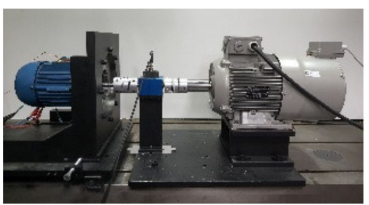

(c)

Figure 19. (a) Sketch and (b) assembled parts of the stator and skewed rotor of the BDFRM prototype under test, and (c) setup for testing the prototype at different speeds.

Table 5. Specifications of the BDFRM prototype.

\begin{tabular}{cc}
\hline Parameter & Value \\
\hline Rated power $(\mathrm{kW})$ & 1.0 \\
Rated speed $(\mathrm{rpm})$ & 750 \\
Stator inner/outer diameter $(\mathrm{mm})$ & $(92.15 \pm 0.01) /(139.8 \pm 0.01)$ \\
Air gap/Stack length $(\mathrm{mm})$ & $(0.195 \pm 0.02) /(116.15 \pm 0.025)$ \\
$p_{g} / p_{c} / p_{r}$ & $2 / 4 / 6$ \\
$\beta / \tau(\mathrm{deg})$ & $10.3 / 15.2$ \\
Total numbers of turns in series $N_{g} / N_{c}$ & $198 / 369$ \\
Parallel circuits in grid/control winding $c_{g} / c_{c}$ & $2 / 1$ \\
Carter's coefficient $k_{c}$ & 1.22 \\
\hline
\end{tabular}

The turns functions of the grid and control windings are depicted in Figure 20a,b, respectively.

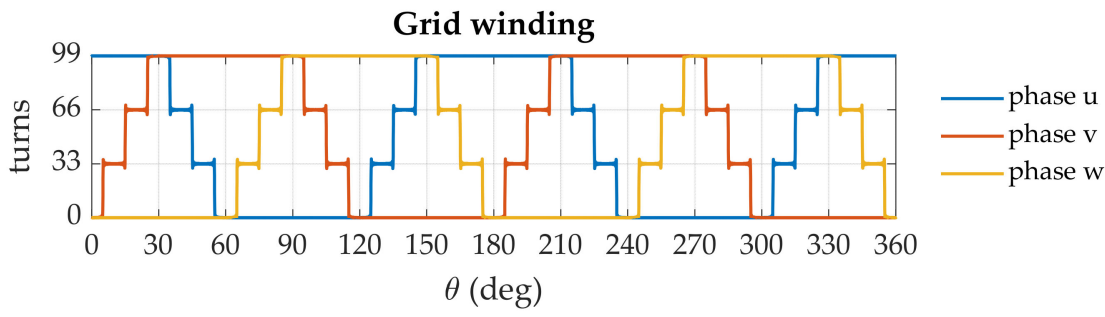

(a)

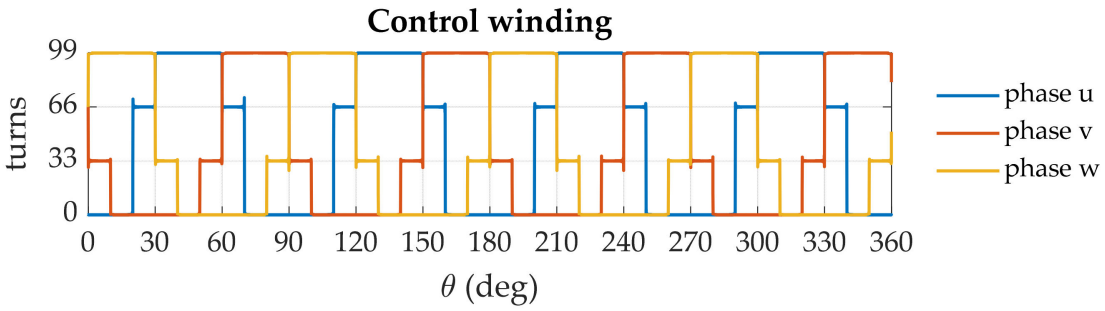

(b)

Figure 20. Turns functions of (a) the grid winding and (b) the control winding of the BDFRM prototype under test. 
To measure the mutual inductance, the induced voltage in the grid winding is measured while injecting a constant DC current $\mathrm{I}_{\mathrm{uc}}$ in phase $\mathrm{u}$ of the control winding and rotating the rotor at constant speed $\Omega_{\mathrm{r}}$. This is schematically represented in Figure 21 .

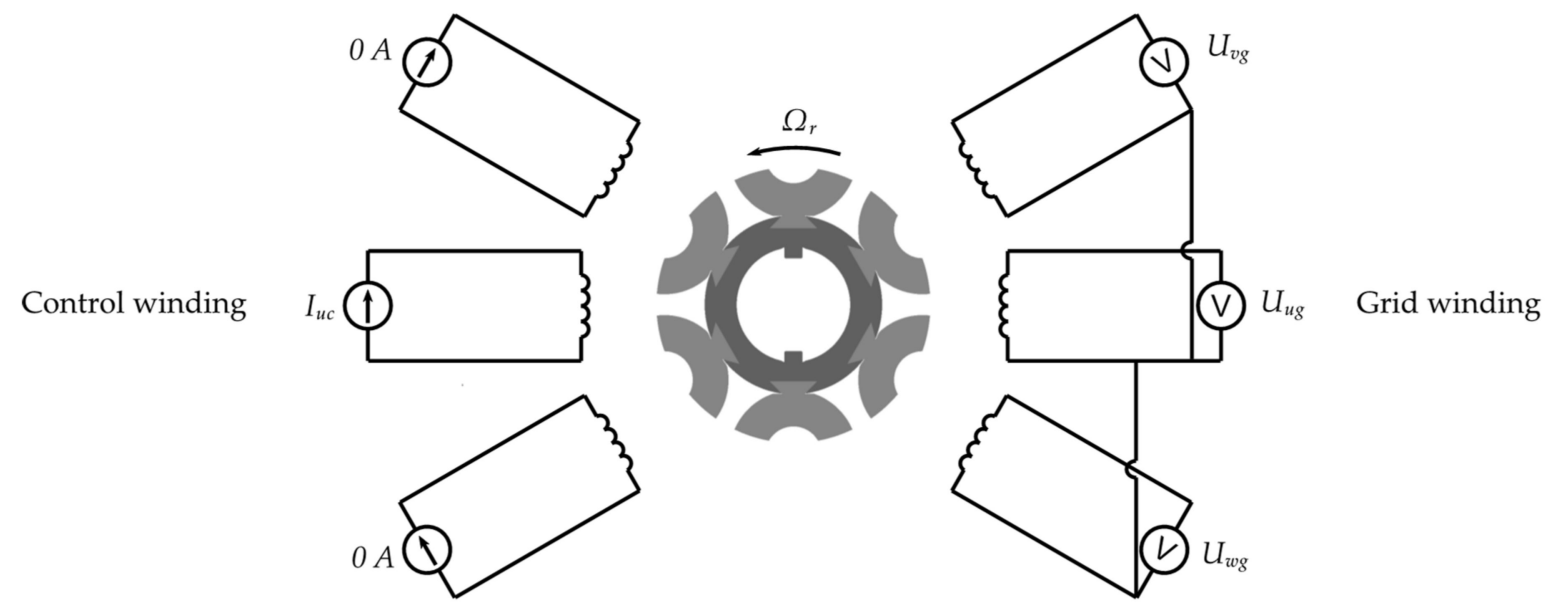

Figure 21. Electrical circuit of the BDFRM prototype while performing a mutual inductance measurement.

The analytical estimates for the peak value of the mutual inductances $\mathrm{M}_{\mathrm{ig} \text {,uc }}$ are calculated with Equation (43), where the stator Carter's coefficient and the number of parallel circuits are included.

$$
\mathrm{M}_{\mathrm{ig}, \mathrm{uc}}=\frac{\mu_{0} \pi \mathrm{R}_{\mathrm{s}} \mathrm{L}}{\mathrm{k}_{\mathrm{c}} \mathrm{g}}\left(\frac{4}{\pi} \frac{\mathrm{k}_{\mathrm{w}, \mathrm{g}} \mathrm{N}_{\mathrm{g}}}{2 \mathrm{p}_{\mathrm{g}} \mathrm{c}_{\mathrm{g}}}\right)\left(\frac{4}{\pi} \frac{\mathrm{k}_{\mathrm{w}, \mathrm{uc}} \mathrm{N}_{\mathrm{c}}}{2 \mathrm{p}_{\mathrm{c}} \mathrm{c}_{\mathrm{c}}}\right) \mathrm{C}_{\mathrm{gc}}
$$

The measured inductances are calculated in Equation (45) with the fundamental components $U_{1, \text { ig }}$ of the induced phase-to-neutral voltages. Both analytically estimated and measured inductance values are compared in Figure 22. The induced phase-to-neutral voltages are depicted in Figure 23 at different rotor speeds.

$$
\mathrm{M}_{\mathrm{ig}, \mathrm{uc}}=\frac{\mathrm{U}_{1, \mathrm{ig}}}{\mathrm{p}_{\mathrm{r}} \Omega_{\mathrm{r}} \mathrm{I}_{\mathrm{uc}}}
$$
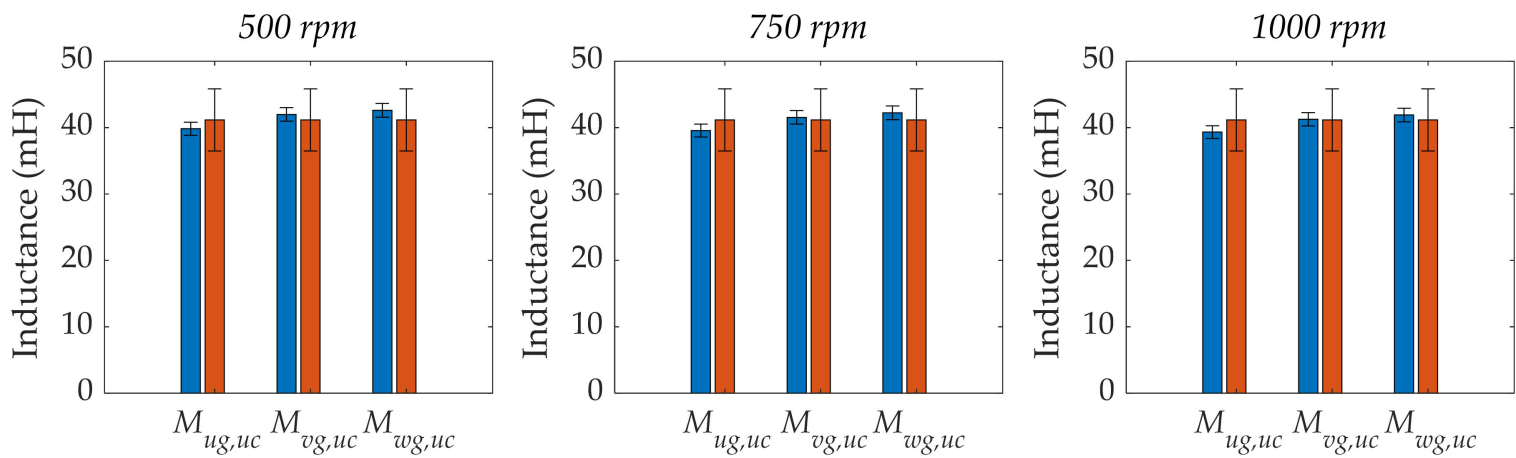

Figure 22. Comparison of measured and analytically estimated inductance values of the mutual inductance at different rotor speeds. 


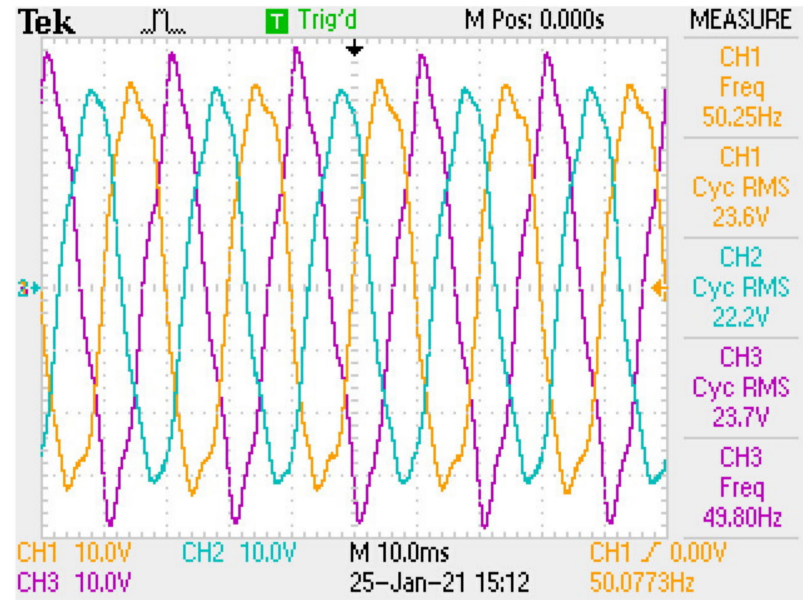

(a)

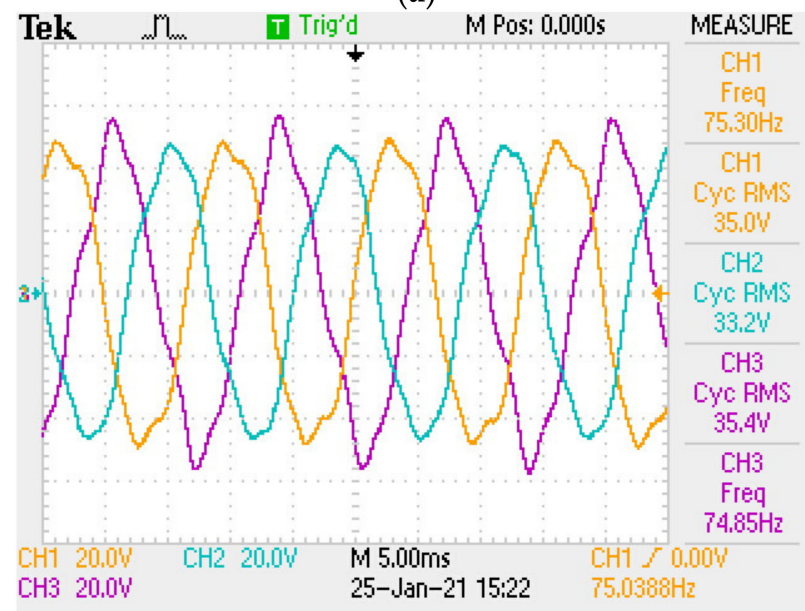

(b)

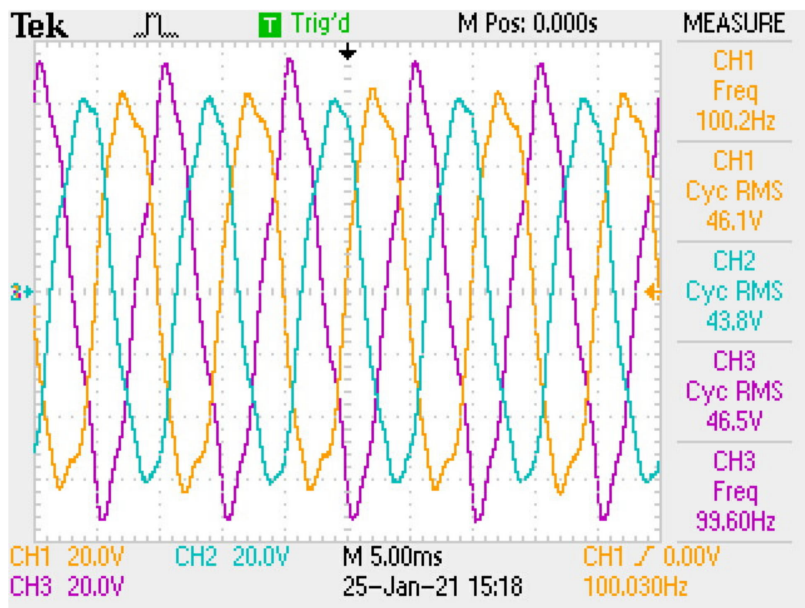

(c)

Figure 23. Induced phase-to-neutral voltages on the grid winding with $2.5 \mathrm{~A}$ through phase a of the grid winding at (a) $500 \mathrm{rpm}$, (b) $750 \mathrm{rpm}$ and (c) $1000 \mathrm{rpm}$.

The results show that the measured mutual inductances fall within the boundaries of the analytical estimates. The boundaries of the latter are relatively large mainly due to the small air gap length of $195 \mu \mathrm{m}$ and the accuracy of its measurement.

\section{Discussion and Conclusions}

The presented models for a DR, DSR and SPR allow BDFRM designers to analytically determine the torque density without resorting to FEA. Until now, the ideal ALR was used as a reference for designing the BDFRM. This approach results in an important under sizing as the ideal ALR has superior performance, due to its ideal nature. In the literature, the under sizing is solved by introducing a saturation factor or oversizing factor which is determined by FEA. The results show that the presented models show a relatively good accuracy for the estimation of the mutual coupling factor for the SPR, DSR with single and multiple flux ducts. The self-coupling factors are well estimated for the SPR thanks to the modeling of the rotor slots. For the DSR with single flux duct, the inaccuracy on the self-coupling factors is relatively high, yet better than the ideal ALR model. When increasing the number of flux ducts and the proximity of neighboring segments, the ALR model is more suited for the self-coupling coefficients.

The mutual coupling factor estimation was validated on a BDFRM prototype with a DSR with single flux guide through the measurement of mutual inductances. The measured inductance values fall within the boundaries of the analytical estimates, without resorting to any kind of compensation factor, thus validating the presented model. 
Whereas the presented model accurately estimates the torque density though the mutual coupling, the power factor estimation, which also depends on the self-coupling factors, still needs improvement. The self-coupling factors depend more heavily on leakage flux and flux paths that are not captured yet in the presented models. Improving the self-coupling factors estimation will open the path to analytical optimization of the rotor geometry for torque density and power factor.

Author Contributions: Y.B. conducted the theoretical and experimental research presented in this paper; J.C. contributed to the literature study and reviewed the paper with particular attention to the mathematical derivations; B.V., O.H. and J.V.M. reviewed the paper, supervised the research and contributed to the funding acquisition. All authors have read and agreed to the published version of the manuscript.

Funding: This research was funded by Flanders Innovation \& Entrepreneurship (VLAIO), grant number HBC.2017.0559.

Acknowledgments: We thank VLAIO for the funding of this research and acknowledge Flanders Make for the support to our research group MOBI.

Conflicts of Interest: The authors declare no conflict of interest. The funders had no role in the design of the study; in the collection, analyses, or interpretation of data; in the writing of the manuscript, or in the decision to publish the results.

\section{Abbreviations}

ALR Axially laminated rotor

BDFIM Brushless Doubly Fed Inductance Machine

BDFRM Brushless Doubly Fed Reluctance Machine

DR Ducted rotor

DSR Ducted segmental rotor

FEA Finite Element Analysis

MMF Magnetomotive force

SPR Salient Pole Rotor

SynRM Synchronous Reluctance Motor

\section{Nomenclature}

Symbol Meaning

$B_{r} \quad$ Radial component of air gap the flux density in (T)

$C_{C} \quad$ Self-coupling factor of the control winding

$C_{c g} \quad$ Mutual coupling factor of the control winding

$C_{g} \quad$ Grid winding coefficient

$C_{g c} \quad$ Mutual coupling coefficient with grid winding excitation

$C_{n, \text { total }}$ Total Fourier coefficient of a DSR with multiple flux ducts

$c_{c} \quad$ Number of parallel circuits in the control winding

$c_{g} \quad$ Number of parallel circuits in the grid winding

$F \quad$ Amplitude of the stator MMF in (A - turns)

$F_{x, i} \quad$ Amplitude of the stator MMF of phase $i$ of winding $x$ in (A - turns)

$g \quad$ Air gap length in $(\mathrm{m})$

$I_{c} \quad$ RMS phase current in the control winding in (A)

$I_{g} \quad$ RMS phase current in the grid winding in (A)

$k_{c} \quad$ The stator Carter's coefficient

$k_{w, c} \quad$ Fundamental winding factor of the control winding

$k_{w, g} \quad$ Fundamental winding factor of the grid winding

$L \quad$ Stack length in $(\mathrm{m})$

$L_{j x, i x} \quad$ Inductance of phase $j$ of winding $x$ when exciting phase $i$ of winding $x$ in $(\mathrm{H})$

$M_{j x, i y} \quad$ Mutual inductance of phase $j$ of winding $x$ when exciting phase $i$ of winding $y$ in $(\mathrm{H})$ 
$N_{c} \quad$ Number turns in series for the control winding

$N_{D} \quad$ Number of flux ducts per segment

$N_{g} \quad$ Number turns in series for the grid winding

$p_{r} \quad$ Number of rotor poles or segments

$p_{g} \quad$ Pole pair number on the grid winding

$p_{c} \quad$ Pole pair number on the control winding

$R_{g} \quad$ Radius in the middle of the air gap in (m)

$R_{r} \quad$ Rotor outer radius in (m)

$R_{S} \quad$ Stator inner radius in $(\mathrm{m})$

$U_{i} \quad$ Magnetic potential of segment $i$ in (A - turns)

\section{Greek Symbols}

$\beta \quad$ Geometry parameter of the DSR in (rad)

$\gamma \quad$ Load angle in mechanical radians (rad)

$\delta(k) \quad$ Dirac delta function

$\theta_{i} \quad$ Angular position of the d-axis for segment $i$ in mechanical radians (rad)

$\theta_{q i} \quad$ Angular position of the q-axis for segment $i$ in mechanical radians (rad)

$\theta_{r} \quad$ Angular position of the d-axis of the rotor with respect to an arbitrary reference frame in mechanical radians (rad)

$\mu_{0} \quad$ Permeability of air in $(\mathrm{H} / \mathrm{m})$

$\rho_{\text {slots }}$ Dimensionless attenuation factor of the rotor slots

$\tau \quad$ Geometry parameter of the DSR in (rad)

$\phi_{x} \quad$ Phase shift of the stator MMF wave of winding $x$ with respect to an arbitrary reference

$\phi_{x} \quad$ frame in electrical radians (rad)

$\varphi_{x} \quad$ Angular position of the stator MMF wave of winding $x$ with respect to an arbitrary

$\varphi_{x} \quad$ reference frame in electrical radians (rad)

$\Omega_{r} \quad$ Angular velocity of the rotor in mechanical radians per second ( $\mathrm{rad} / \mathrm{s}$ )

$\omega_{x}$ Angular velocity of the stator MMF wave of winding $x$ in electrical radians per second ( $\mathrm{rad} / \mathrm{s})$

\section{Appendix A}

Due to infinite permeability, the induced magnetic field has only a radial component at the interfaces between iron and air, and thus also in the air gap as depicted in Figure A1. Furthermore, the cylindrical symmetry of the machine and the infinitesimal thickness $\delta \theta$ of the rotor segment reduces Gauss's law for a portion of the air gap to Equation (A1). This expresses that the magnitude of the magnetic flux density is constant along any arbitrary radius. The same exercise is performed for the rotor segment while assuming perfectly magnetically insulated segment walls Equation (A2). The magnetic flux density at the 'entry' and 'exit' of the rotor segment can then be expressed as Equation (A3).

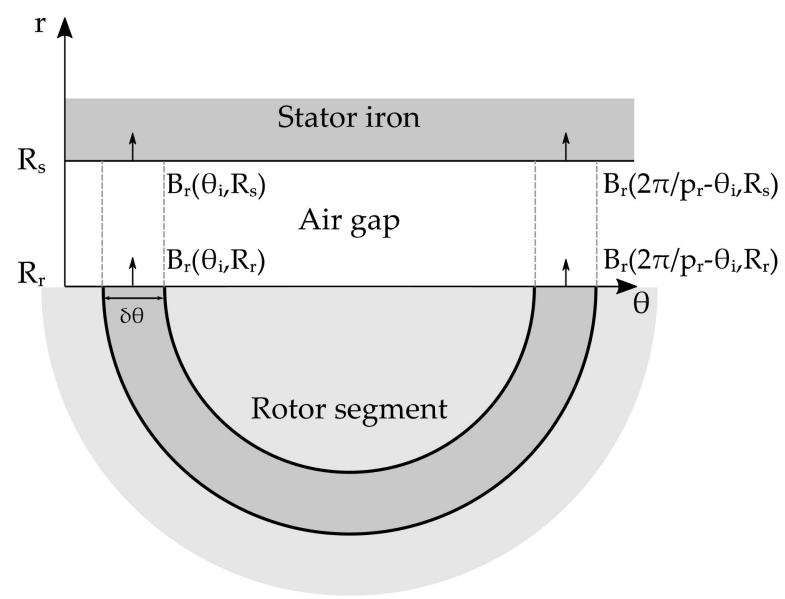

Figure A1. Schematic representation of a rotor segment of an ideal ALR. 


$$
\begin{gathered}
\oint_{\mathrm{V}_{\text {air gap }}} \mathbf{B}_{\mathbf{r}} \cdot \mathbf{d V}=0 \\
\Rightarrow-\mathrm{B}_{\mathrm{r}}\left(\theta_{\mathrm{i}}, \mathrm{R}_{\mathrm{r}}\right) \mathrm{R}_{\mathrm{r}} \delta \theta+\mathrm{B}_{\mathrm{r}}\left(\theta_{\mathrm{i}}, \mathrm{R}_{\mathrm{s}}\right) \mathrm{R}_{\mathrm{s}} \delta \theta=0 \\
\Rightarrow \mathrm{R}_{\mathrm{r}} \mathrm{B}_{\mathrm{r}}\left(\theta_{\mathrm{i}}, \mathrm{R}_{\mathrm{r}}\right)=\mathrm{R}_{\mathrm{s}} \mathrm{B}_{\mathrm{r}}\left(\theta_{\mathrm{i}}, \mathrm{R}_{\mathrm{s}}\right) \\
\oint_{\mathrm{V}_{\text {segment }}} \mathbf{B}_{\mathrm{r}} \cdot \mathbf{d V}=0 \\
\Rightarrow \mathrm{B}_{\mathrm{r}}\left(\theta_{\mathrm{i}}, \mathrm{R}_{\mathrm{r}}\right) \delta \theta+\mathrm{B}_{\mathrm{r}}\left(\frac{2 \pi}{\mathrm{p}_{\mathrm{r}}}-\theta_{\mathrm{i}}, \mathrm{R}_{\mathrm{r}}\right) \delta \theta=0 \\
\Rightarrow \quad \mathrm{B}_{\mathrm{r}}\left(\theta_{\mathrm{i}}, \mathrm{R}_{\mathrm{r}}\right)=-\mathrm{B}_{\mathrm{r}}\left(\frac{2 \pi}{\mathrm{p}_{\mathrm{r}}}-\theta_{\mathrm{i}}, \mathrm{R}_{\mathrm{r}}\right) \\
\mathrm{B}_{\mathrm{r}}\left(\theta_{\mathrm{i}}, \mathrm{R}_{\mathrm{s}}\right)=\frac{\mathrm{B}_{\mathrm{r}}\left(\theta_{\mathrm{i}}, \mathrm{R}_{\mathrm{s}}\right)+\frac{\mathrm{R}_{\mathrm{r}}}{\mathrm{R}_{\mathrm{s}}} \mathrm{B}_{\mathrm{r}}\left(\theta_{\mathrm{i}}, \mathrm{R}_{\mathrm{r}}\right)}{2}=\frac{\mathrm{B}_{\mathrm{r}}\left(\theta_{\mathrm{i}}, \mathrm{R}_{\mathrm{s}}\right)-\mathrm{B}_{\mathrm{r}}\left(\frac{2 \pi}{\mathrm{p}_{\mathrm{r}}}-\theta_{\mathrm{i}}, \mathrm{R}_{\mathrm{s}}\right)}{2}
\end{gathered}
$$

Finally, the magnetic flux density in the air gap can be rewritten in terms of the MMF along the stator inner radius Equation (A4).

$$
\mathrm{B}_{\mathrm{r}}\left(\theta_{\mathrm{i}}\right)=\frac{\mu_{0}}{\mathrm{~g}} \frac{\mathrm{F}\left(\theta_{\mathrm{i}}\right)-\mathrm{F}\left(\frac{2 \pi}{\mathrm{p}_{\mathrm{r}}}-\theta_{\mathrm{i}}\right)}{2}
$$

\section{Appendix B}

This section will detail the derivation of Equation (8), based on Equations (5) and (6), for a an original MMF wave that is described by a cosine function as in Equation (7). First, the pulse function is rewritten as a complex Fourier series Equation (A5) and injected in the expression for the modulated MMF Equation (A6).

$$
\text { pulse }(\theta)=\frac{1}{\operatorname{pr}_{\mathrm{r}}} \sum_{\mathrm{k}=-\infty}^{+\infty} \sin \mathrm{c}\left(\frac{\mathrm{k} \pi}{\mathrm{p}_{\mathrm{r}}}\right) \mathrm{e}^{\mathrm{j} \mathrm{k} \theta}=\left\{\begin{array}{cc}
1 & \text { if } \theta \in\left[-\pi / \mathrm{p}_{\mathrm{r}}, \pi / \mathrm{p}_{\mathrm{r}}\right] \\
0 & \text { else }
\end{array}\right.
$$

$$
\mathrm{F}_{\mathrm{m}}\left(\theta, \theta_{\mathrm{r}}\right)=\frac{\mathrm{F}}{2} \cos \left(\mathrm{p}_{\mathrm{s}} \theta-\varphi_{\mathrm{s}}(\mathrm{t})\right)-\frac{\mathrm{F}}{2 \mathrm{p}_{\mathrm{r}}} \sum_{\mathrm{i}=0}^{\mathrm{p}_{\mathrm{r}}-1} \cos \left(\mathrm{p}_{\mathrm{s}}\left((2 \mathrm{i}+1) \frac{2 \pi}{\mathrm{p}_{\mathrm{r}}}-\theta+2 \theta_{\mathrm{r}}\right)-\varphi_{\mathrm{s}}(\mathrm{t})\right) \cdot\left(\sum_{\mathrm{k}=-\infty}^{+\infty} \sin \mathrm{c}\left(\frac{\mathrm{k}}{\mathrm{p}_{\mathrm{r}}}\right) \mathrm{e}^{\mathrm{j} \mathrm{k}\left(\theta-(2 \mathrm{i}+1) \frac{\pi}{\mathrm{p}_{\mathrm{r}}}-\theta_{\mathrm{r}}\right)}\right)
$$

The second term, containing the sum over index $\mathrm{i}$, is expanded further using complex numbers in Equation (A7).

$$
\begin{array}{r}
\sum_{i=0}^{p_{r}-1} \cos \left(p_{s}\left((2 i+1) \frac{2 \pi}{p_{r}}-\theta+2 \theta_{r}\right)-\varphi_{s}(t)\right) \cdot\left(\sum_{k=-\infty}^{+\infty} \sin c\left(\frac{k}{p_{r}}\right) e^{j k\left(\theta-(2 i+1) \frac{\pi}{p_{r}}-\theta_{r}\right)}\right) \\
\sum_{i=0}^{p_{r}-1} \frac{e^{j p_{s}\left((2 i+1) \frac{2 \pi}{p_{r}}-\theta+2 \theta_{r}\right)-j \varphi_{s}(t)}+e^{-j p_{s}\left((2 i+1) \frac{2 \pi}{p_{r}}-\theta+2 \theta_{r}\right)+j \varphi_{s}(t)}}{2}\left(\sum_{k=-\infty}^{+\infty} \operatorname{sinc}\left(\frac{k}{p_{r}}\right) e^{j k\left(\theta-(2 i+1) \frac{\pi}{p_{r}}-\theta_{r}\right)}\right) \\
=\frac{1}{2} \sum_{k=-\infty}^{+\infty} \operatorname{sinc}\left(\frac{k}{p_{r}}\right) \sum_{i=0}^{p_{r}-1}\left(e^{j p_{s}\left((2 i+1) \frac{2 \pi}{p_{r}}-\theta+2 \theta_{r}\right)-j \varphi_{s}(t)}+e^{-j p_{s}\left((2 i+1) \frac{2 \pi}{p_{r}}-\theta+2 \theta_{r}\right)+j \varphi_{s}(t)}\right) e^{j k\left(\theta-(2 i+1) \frac{\pi}{p_{r}}-\theta_{r}\right)} \\
\sum_{k=-\infty} \operatorname{sinc}\left(\frac{k}{p_{r}}\right) \sum_{i=0}^{p_{r}-1}\left(e^{j\left[p_{s}\left((2 i+1) \frac{2 \pi}{p_{r}}-\theta+2 \theta_{r}\right)+k\left(\theta-(2 i+1) \frac{\pi}{p_{r}}\right)-k \theta_{r}-\varphi_{s}(t)\right]}+e^{j\left[-p_{s}\left((2 i+1) \frac{2 \pi}{p_{r}}-\theta+2 \theta_{r}\right)+k\left(\theta-(2 i+1) \frac{\pi}{p_{r}}\right)-k \theta_{r}+\varphi_{s}(t)\right]}\right) \\
=\frac{1}{2} \sum_{k=-\infty}^{+\infty} \operatorname{sinc}\left(\frac{k}{p_{r}}\right)\left(e^{j\left(k-p_{s}\right) \theta-\left(k-2 p_{s}\right) \theta_{r}-\varphi} \sum_{i=0}^{p_{r}-1} e^{j(2 i+1) \frac{\pi}{p_{r}}\left(2 p_{s}-k\right)}+e^{j\left(k+p_{s}\right) \theta-\left(k+2 p_{s}\right) \theta_{r}+\varphi} \sum_{i=0}^{p_{r}-1} e^{-j(2 i+1) \frac{\pi}{p_{r}}\left(2 p_{s}+k\right)}\right)
\end{array}
$$

The sums over index i Equations (A9) and (A10) can now be calculated using the finite sum Equation (A8).

$$
\sum_{i=0}^{N} \mathrm{e}^{\mathrm{j}(\mathrm{i} \alpha+\beta)}=\frac{\sin \frac{(\mathrm{N}+1) \alpha}{2}}{\sin \frac{\alpha}{2}} \mathrm{e}^{\mathrm{j}\left(\beta+\frac{\mathrm{N} \alpha}{2}\right)}
$$




$$
\begin{gathered}
\sum_{i=0}^{p_{r}-1} e^{j(2 i+1) \frac{\pi}{p_{r}}\left(2 p_{s}-k\right)} \\
=\sum_{i=0}^{p_{r}-1} e^{j\left(i\left(\frac{2 \pi}{p_{r}}\left(2 p_{s}-k\right)\right)+\frac{\pi}{p_{r}}\left(2 p_{s}-k\right)\right)} \\
=\frac{\sin \left(\pi\left(2 p_{s}-k\right)\right)}{\sin \left(\frac{\pi}{p_{r}}\left(2 p_{s}-k\right)\right)} e^{j\left(\frac{\pi}{p_{r}}\left(2 p_{s}-k\right)+\left(p_{r}-1\right) \frac{\pi}{p_{r}}\left(2 p_{s}-k\right)\right)} \\
\Rightarrow \sum_{i=0}^{p_{r}-1} e^{j(2 i+1) \frac{\pi}{p_{r}}\left(2 p_{s}-k\right)}=\left\{\begin{array}{cc}
(-1)^{n} p_{r} & \text { if } \quad\left(2 p_{s}-k\right)=n p_{r} \quad \text { with } n \in Z \\
0 & \text { else }
\end{array}\right. \\
\sum_{i=0}^{p_{r}-1} e^{j(2 i+1) \frac{\pi}{p_{r}}\left(2 p_{s}+k\right)}=\left\{\begin{array}{ccl}
(-1)^{n} p_{r} & \text { if } \quad\left(2 p_{s}+k\right)=n p_{r} \quad \text { with } n \in Z \\
0 & \text { else }
\end{array}\right.
\end{gathered}
$$

Finally, the sum over k in Equation (A7) can be rewritten as Equation (A11) and thereby, expression Equation (8) is proven.

$$
\begin{gathered}
\frac{1}{p_{r}} \sum_{i=0}^{p_{r}-1} \cos \left((2 i+1) \frac{2 \pi}{p_{r}}-\theta+2 \theta_{r}-\varphi_{s}(t)\right) \cdot\left(\sum_{k=-\infty}^{+\infty} \operatorname{sinc}\left(\frac{k}{p_{r}}\right) e^{j k\left(\theta-(2 i+1) \frac{\pi}{p_{r}}-\theta_{r}\right)}\right) \\
=\frac{1}{2} \sum_{n=-\infty}^{+\infty}(-1)^{n} \operatorname{sinc}\left(\frac{2 p_{s}-n p_{r}}{p_{r}}\right) e^{j\left(p_{s}-n p_{r}\right) \theta+j n p_{r} \theta_{r}-j \varphi_{s}(t)} \\
+\frac{1}{2} \sum_{n=-\infty}^{+\infty}(-1)^{n} \operatorname{sinc}\left(-\frac{2 p_{s}-n p_{r}}{p_{r}}\right) e^{j\left(n p_{r}-p_{s}\right) \theta-j n p_{r} \theta_{r}+j \varphi_{s}(t)} \\
=\frac{1}{2} \sum_{n=-\infty}^{+\infty}(-1)^{n} \operatorname{sinc} c\left(\frac{2 p_{s}-n p_{r}}{p_{r}}\right)\left(e^{j\left(p_{s}-n p_{r}\right) \theta+j n p_{r} \theta_{r}-j \varphi_{s}(t)}+e^{j\left(n p_{r}-p_{s}\right) \theta-j n p_{r} \theta_{r}+j \varphi_{s}(t)}\right) \\
=\sum_{n=-\infty}^{+\infty}(-1)^{n} \operatorname{sinc} c\left(\frac{2 p_{s}-n p_{r}}{p_{r}}\right) \cos \left(\left(p_{s}-n p_{r}\right) \theta+n p_{r} \theta_{r}-\varphi_{s}(t)\right)
\end{gathered}
$$

\section{Appendix C}

In this section, the analytical expression is derived for the energy, and coenergy in the case of linear magnetic behavior, stored in the air gap of a BDFRM with an ideal ALR.

$$
\begin{gathered}
\mathrm{W}\left(\theta_{\mathrm{r}}, \mathrm{t}\right)=\frac{1}{2 \mu_{0}} \int_{\mathrm{V}_{\text {air gap }}} \mathrm{B}_{\mathrm{r}}\left(\theta, \theta_{\mathrm{r}}, \mathrm{t}\right)^{2} \mathrm{dV} \\
=\frac{1}{2 \mu_{0}} \int_{0}^{\mathrm{L}} \int_{\mathrm{R}_{\mathrm{s}}-\mathrm{g}}^{\mathrm{R}_{\mathrm{s}}} \int_{0}^{2 \pi} \mathrm{B}_{\mathrm{r}}\left(\theta, \theta_{\mathrm{r}}, \mathrm{t}\right)^{2} \mathrm{R}_{\mathrm{s}} \mathrm{d} \theta \mathrm{drdz} \\
=\frac{\mathrm{gR} \mathrm{s}}{2 \mu_{0}} \int_{0}^{2 \pi} \mathrm{B}_{\mathrm{r}}\left(\theta, \theta_{\mathrm{r}}, \mathrm{t}\right)^{2} \mathrm{~d} \theta \\
=\frac{\mu_{0}}{\mathrm{~g}} \frac{\mathrm{R}_{\mathrm{s}} \mathrm{L}}{2} \int_{0}^{2 \pi} \mathrm{F}_{\mathrm{m}}\left(\theta, \theta_{\mathrm{r}}, \mathrm{t}\right)^{2} \mathrm{~d} \theta \\
=\frac{\mu_{0}}{\mathrm{~g}} \frac{\mathrm{R}_{\mathrm{s}} \mathrm{L}}{2} \int_{0}^{2 \pi}\left(\mathrm{F}_{\mathrm{mg}}\left(\theta, \theta_{\mathrm{r}}, \mathrm{t}\right)+\mathrm{F}_{\mathrm{mc}}\left(\theta, \theta_{\mathrm{r}}, \mathrm{t}\right)\right)^{2} \mathrm{~d} \theta
\end{gathered}
$$

To calculate the integrals, the modulated MMF waves are rewritten as Equation (A13) with new coefficients $\mathrm{C}_{\mathrm{xk}}$ defined by Equation (A14).

$$
\begin{array}{r}
\mathrm{F}_{\mathrm{mx}}\left(\theta, \theta_{\mathrm{r}}, \mathrm{t}\right)=\mathrm{F}_{\mathrm{x}} \sum_{\mathrm{k}=-\infty}^{+\infty} \mathrm{C}_{\mathrm{x}, \mathrm{k}} \cos \left(\left(\mathrm{p}_{\mathrm{x}}+\mathrm{k} \mathrm{p}_{\mathrm{r}}\right) \theta-\mathrm{kp}_{\mathrm{r}} \theta_{\mathrm{r}}-\varphi_{\mathrm{x}}(\mathrm{t})\right) \\
\mathrm{C}_{\mathrm{x}, \mathrm{k} \neq 0}=-\frac{1}{2}(-1)^{\mathrm{k}} \sin \mathrm{c}\left(\frac{2 \mathrm{p}_{\mathrm{x}}+\mathrm{k} \mathrm{p}_{\mathrm{r}}}{\mathrm{p}_{\mathrm{r}}}\right) \mathrm{C}_{\mathrm{x}, \mathrm{k}=0}=\frac{1}{2}-\frac{1}{2}(-1)^{\mathrm{k}} \sin \mathrm{c}\left(\frac{2 \mathrm{p}_{\mathrm{x}}}{\mathrm{p}_{\mathrm{r}}}\right)
\end{array}
$$

Based on integral Equation (A15) that can be proven using trigonometric identities, the integrals Equations (A16)-(A18) are calculated. The coenery is the sum of these integrals.

$$
\begin{gathered}
\int_{0}^{2 \pi} \cos \left(\mathrm{p}_{\mathrm{x}} \theta+\alpha\right) \cdot \cos \left(\mathrm{p}_{\mathrm{y}} \theta+\beta\right) \mathrm{d} \theta=\left\{\begin{array}{cc}
0 & \text { if } \mathrm{p}_{\mathrm{x}} \neq \mathrm{p}_{\mathrm{y}} \\
\pi \cos (\alpha-\beta) & \text { if } \mathrm{p}_{\mathrm{x}}=\mathrm{p}_{\mathrm{y}}
\end{array}\right. \\
\int_{0}^{2 \pi} \mathrm{F}_{\mathrm{mg}}\left(\theta, \theta_{\mathrm{r}}, \mathrm{t}\right)^{2} \mathrm{~d} \theta=\pi \mathrm{F}_{\mathrm{g}}^{2} \sum_{\mathrm{k}=-\infty}^{+\infty} \mathrm{C}_{\mathrm{g}, \mathrm{k}}^{2}
\end{gathered}
$$




$$
\begin{gathered}
\int_{0}^{2 \pi} F_{m c}\left(\theta, \theta_{r}, t\right)^{2} d \theta=\pi F_{c}^{2} \sum_{k=-\infty}^{+\infty} C_{c, k}^{2} \\
\int_{0}^{2 \pi} 2 F_{m g}\left(\theta, \theta_{r}, t\right) F_{m c}\left(\theta, \theta_{r}, t\right) d \theta \\
=2 \pi F_{g} F_{c} \cos \left(p_{r} \theta-\varphi_{g}(t)-\varphi_{c}(t)\right) \sum_{k=-\infty}^{+\infty} C_{g, k} C_{c,-(k+1)}
\end{gathered}
$$

The sum in Equation (A18) contains the mutual coupling factors $\mathrm{C}_{\mathrm{gc}}$ and $\mathrm{C}_{\mathrm{cg}}$ and an additional sum as detailed in Equation (A19). It can be verified numerically that the latter is at least $10^{-4}$ times smaller than the sum $\frac{\mathrm{C}_{\mathrm{gc}}+\mathrm{C}_{\mathrm{cg}}}{2}$, and this for any $\mathrm{p}_{\mathrm{g}} \neq \mathrm{p}_{\mathrm{c}}$ for which Equation (13) is valid.

$$
\begin{gathered}
\sum_{\mathrm{k}=-\infty}^{+\infty} \mathrm{C}_{\mathrm{g}, \mathrm{k}} \mathrm{C}_{\mathrm{c},-(\mathrm{k}+1)} \\
=\frac{1}{4} \sum_{\mathrm{k}=-\infty}^{+\infty}\left(\delta(\mathrm{k})-(-1)^{\mathrm{k}} \operatorname{sinc}\left(\frac{2 \mathrm{p}_{\mathrm{g}}+\mathrm{k} \mathrm{p}_{\mathrm{r}}}{\mathrm{p}_{\mathrm{r}}}\right)\right) \cdot\left(\delta(-(\mathrm{k}+1))-(-1)^{-(\mathrm{k}+1)} \sin \mathrm{c}\left(\frac{2 \mathrm{p}_{\mathrm{c}}-(\mathrm{k}+1) \mathrm{p}_{\mathrm{r}}}{\mathrm{p}_{\mathrm{r}}}\right)\right) \\
=\frac{1}{4} \sum_{\mathrm{k}=-\infty}^{+\infty}\left(\delta(\mathrm{k})-(-1)^{\mathrm{k}} \sin \mathrm{c}\left(\frac{2 \mathrm{p}_{\mathrm{g}}+\mathrm{kp}_{\mathrm{r}}}{\mathrm{p}_{\mathrm{r}}}\right)\right) \cdot\left(\delta(-(\mathrm{k}+1))+(-1)^{\mathrm{k}} \operatorname{sinc} \mathrm{c}\left(\frac{2 \mathrm{p}_{\mathrm{c}}-(\mathrm{k}+1) \mathrm{p}_{\mathrm{r}}}{\mathrm{p}_{\mathrm{r}}}\right)\right) \\
=\frac{1}{4}\left(\operatorname{sinc}\left(\frac{2 \mathrm{p}_{\mathrm{g}}-\mathrm{p}_{\mathrm{r}}}{\mathrm{p}_{\mathrm{r}}}\right)+\operatorname{sinc}\left(\frac{2 \mathrm{p}_{\mathrm{c}}-\mathrm{p}_{\mathrm{r}}}{\mathrm{p}_{\mathrm{r}}}\right)-\sum_{\mathrm{k}=-\infty}^{+\infty} \operatorname{sinc}\left(\frac{2 \mathrm{p}_{\mathrm{g}}+\mathrm{kp}_{\mathrm{r}}}{\mathrm{p}_{\mathrm{r}}}\right) \operatorname{sinc}\left(\frac{2 \mathrm{p}_{\mathrm{c}}-(\mathrm{k}+1) \mathrm{p}_{\mathrm{r}}}{\mathrm{p}_{\mathrm{r}}}\right)\right) \\
=\frac{1}{4}\left(2 \mathrm{C}_{\mathrm{gc}}+2 \mathrm{C}_{\mathrm{cg}}-\sum_{\mathrm{k}=-\infty}^{+\infty} \operatorname{sinc}\left(\frac{2 \mathrm{p}_{\mathrm{g}}+\mathrm{k} \mathrm{p}_{\mathrm{r}}}{\mathrm{p}_{\mathrm{r}}}\right) \operatorname{sinc}\left(\frac{2 \mathrm{p}_{\mathrm{c}}-(\mathrm{k}+1) \mathrm{p}_{\mathrm{r}}}{\mathrm{p}_{\mathrm{r}}}\right)\right) \\
\approx \frac{\mathrm{C}_{\mathrm{gc}}+\mathrm{C}_{\mathrm{cg}}}{2}
\end{gathered}
$$

\section{References}

1. Liang, F.; Xu, L.; Lipo, T.A. d-q Analysis of a variable speed doubly AC excited reluctance motor. Electr. Mach. Power Syst. 1991, 19, 125-138. [CrossRef]

2. Jovanovic, M.G.; Betz, R.E.; Yu, J. The use of doubly fed reluctance machines for large pumps and wind turbines. IEEE Trans. Ind. Appl. 2002, 38, 1508-1516. [CrossRef]

3. Dorrell, D.G.; Jovanovic, M. On the Possibilities of Using a Brushless Doubly-Fed Reluctance Generator in a 2 MW Wind Turbine. In Proceedings of the 2008 IEEE Industry Applications Society Annual Meeting, Edmonton, AB, Canada, 5-9 October 2008; pp. 1-8.

4. Protsenko, K.; Xu, D. Modeling and Control of Brushless Doubly-Fed Induction Generators in Wind Energy Applications. In Proceedings of the APEC 07-Twenty-Second Annual IEEE Applied Power Electronics Conference and Exposition, Anaheim, CA, USA, 25 February-1 March 2007; pp. 529-535.

5. Gorti, B.V.; Zhou, D.; Spee, R.; Alexander, G.C.; Wallace, A.K. Development of a Brushless Doubly-Fed Machine for a LimitedSpeed Pump Drive in a Waste-Water Treatment Plant. In Proceedings of the 1994 IEEE Industry Applications Society Annual Meeting, Denver, CO, USA, 2-5 October 1994.

6. Xu, L; Tang, Y. A Novel Wind-Power Generating System Using Field Orientation Controlled Doubly-Excited Brushless Reluctance Machine. In Proceedings of the 1992 IEEE Industry Applications Society Annual Meeting, Houston, TX, USA, 4-9 October 1992.

7. Agrawal, S.; Province, A.; Banerjee, A. An Approach to Maximize Torque Density in a Brushless Doubly Fed Reluctance Machine. IEEE Trans. Ind. Appl. 2020, 56, 4829-4838. [CrossRef]

8. Hunt, L.J. A new type of induction motor. J. Inst. Electr. Eng. 1907, 39, 648-667. Available online: https:/ / digital-library.theiet. org/content/journals/10.1049/jiee-1.1907.0074 (accessed on 28 April 2020). [CrossRef]

9. Broadway, A.R.W. Cageless induction machine. Engineering 1971, 118, 1593. [CrossRef]

10. Broadway, A.R.W.; Burbridge, L. Self-cascaded machine: A low-speed motor or high-frequency brushless alternator. Eng. Comput. Sci. 1970, 117, 1277. [CrossRef]

11. Broadway, A.R.W.; Cook, B.J.; Neal, P.W. Brushless cascade alternator. Engineering 1974, 121, 1529. [CrossRef]

12. Broadway, A.R.W.; Tan, S.C.F. Brushless stator-controlled synchronous-induction machine. Proc. Inst. Electr. Eng. 1973, 120, 860. [CrossRef]

13. Jovanovic, M.G.; Betz, R.E. Power Factor Control Using Brushless Doubly Fed Reluctance Machines. In Proceedings of the IAS Annual Meeting (IEEE Industry Applications Society), Rome, Italy, 8-12 October 2000.

14. Wang, F.; Zhang, F.; Xu, L. Parameter and performance comparison of doubly fed brushless machine with cage and reluctance rotors. IEEE Trans. Ind. Appl. 2002, 38, 1237-1243. Available online: https:/ / ieeexplore.ieee.org/abstract/document/1035175 (accessed on 28 April 2020). [CrossRef] 
15. Xu, L.; Wang, F. Comparative Study of Magnetic Coupling for a Doubly Fed Brushless Machine with Reluctance and Cage Rotors. In Proceedings of the IAS'97. Conference Record of the 1997 IEEE Industry Applications Conference Thirty-Second IAS Annual Meeting, New Orleans, LA, USA, 5-9 October 1997; pp. 326-332.

16. Xu, L.; Zhen, L.; Kim, E.-H. Field Orientation Control of a Doubly Excited Brushless Reluctance Machine. In Proceedings of the IAS'96. Conference Record of the 1996 IEEE Industry Applications Conference Thirty-First IAS Annual Meeting, San Diego, CA, USA, 6 August 2002; pp. 319-325.

17. Zhang, F.; Yu, S.; Wang, H.; Wang, Y.; Wang, D. Overview of research and development status of brushless doubly-fed machine system. Chin. J. Electr. Eng. 2016, 2, 1-13.

18. Han, P.; Cheng, M.; Ademi, S.; Jovanovic, M.G. Brushless Doubly-Fed Machines: Opportunities and Challenges. Chin. J. Electr. Eng. 2018, 4, 1-17. Available online: https:/ /ieeexplore.ieee.org/abstract/document/7933122 (accessed on 28 April 2020).

19. Vagati, A. The Synchronous Reluctance Solution: A New Alternative in AC Drives. In Proceedings of the IECON'94-20th Annual Conference of IEEE Industrial Electronics, Bologna, Italy, 5-9 September 1994; pp. 1-13.

20. Scian, I.; Dorrell, D.G.; Holik, P.J. Assessment of Losses in a Brushless Doubly-Fed Reluctance Machine. IEEE Trans. Magn. 2006, 42, 3425-3427. [CrossRef]

21. Liao, Y.; Xu, L.; Zhen, L. Design of a doubly fed reluctance motor for adjustable-speed drives. IEEE Trans. Ind. Appl. 1996, 32, 1195-1203. [CrossRef]

22. Han, P.; Zhang, J.; Cheng, M. Analytical Analysis and Performance Characterization of Brushless Doubly Fed Machines With Multibarrier Rotors. IEEE Trans. Ind. Appl. 2019, 55, 5758-5767. [CrossRef]

23. Vagati, A. Synchronous Reluctance Electrical Motor Having a Low Torque-Ripple Design. US Patent US5818140A, 6 October 1998. Available online: https:/ / patents.google.com/patent/US5818140A/en (accessed on 28 April 2020).

24. Vagati, A.; Pastorelli, M.; Francheschini, G.; Petrache, S.C. Design of low-torque-ripple synchronous reluctance motors. IEEE Trans. Ind. Appl. 1998, 34, 758-765. [CrossRef]

25. Dorrell, D.G.; Knight, A.M.; Betz, R.E. Improvements in Brushless Doubly Fed Reluctance Generators Using High-Flux-Density Steels and Selection of the Correct Pole Numbers. IEEE Trans. Magn. 2011, 47, 4092-4095. [CrossRef]

26. Dorrell, D.G.; Knight, A.M.; Song, W.K.; Betz, R.E. Saturation and Ducting Effects in a Brushless Doubly-Fed Reluctance Machine. IEEE Trans. Magn. 2013, 49, 3933-3936. [CrossRef]

27. Knight, A.M.; Betz, R.E.; Song, W.K.; Dorrell, D.G. Brushless Doubly-Fed Reluctance Machine Rotor Design. In Proceedings of the 2012 IEEE Energy Conversion Congress and Exposition (ECCE), Raleigh, NC, USA, 15-20 September 2012; pp. $2308-2315$.

28. Cheng, M.; Han, P.; Du, Y.; Wen, H.; Li, X. A Tutorial on General Air-gap Field Modulation Theory for Electric Machines. IEEE J. Emerg. Sel. Top. Power Electron. 2021, 1. [CrossRef]

29. Han, P.; Zhang, J.; Cheng, M. Theoretical and Experimental Investigation of the Brushless Doubly-Fed Machine with a MultiBarrier Rotor. In Proceedings of the 2018 IEEE Energy Conversion Congress and Exposition (ECCE), Portland, OR, USA, 23-27 September 2018; pp. 4964-4971.

30. Rebeiro, R.S.; Knight, A.M. Two-Converter-Based Frequency-Sharing Operation and Control of a Brushless Doubly Fed Reluctance Motor Drive. IEEE Trans. Ind. Appl. 2019, 55, 5873-5880. [CrossRef]

31. Rebeiro, R.S.; Knight, A.M. Design and torque capability of a ducted rotor brushless doubly fed reluctance machine. IET Electr. Power Appl. 2018, 12, 1058-1064. [CrossRef]

32. Rebeiro, R.S.; Knight, A.M. Characterization of a Ducted Rotor Brushless Doubly Fed Reluctance Machine. IEEE Trans. Energy Convers. 2019, 34, 79-87. [CrossRef]

33. Liu, H.; Xu, L. Design and Performance Analysis of a Doubly Excited Brushless Machine for Wind Power Generator Application. In Proceedings of the 2nd International Symposium on Power Electronics for Distributed Generation Systems, Hefei, China, 16-18 June 2010.

34. Betz, R.E.; Jovanovic, M.G. Brushless Doubly Fed Reluctance Machines-A Tutorial. 2003. Available online: https:/ / citeseerx.ist. psu.edu/viewdoc/download?doi=10.1.1.565.8777\&rep=rep1\&type=pdf (accessed on 28 April 2020).

35. Betz, R.E.; Jovanovic, M. Introduction to Brushless Doubly Fed Reluctance Machines—The Basic Equations; University of Newcastle: Newcastle, Australia, 1998. [CrossRef]

36. Knight, A.M.; Betz, R.E.; Dorrell, D.G. Design and Analysis of Brushless Doubly Fed Reluctance Machines. IEEE Trans. Ind. Appl. 2013, 49, 50-58. [CrossRef]

37. Cheng, M.; Han, P.; Hua, W. General Airgap Field Modulation Theory for Electrical Machines. IEEE Trans. Ind. Electron. 2017, 64, 6063-6074. [CrossRef]

38. Lubin, T.; Mezani, S.; Rezzoug, A. 2-D Exact Analytical Model for Surface-Mounted Permanent-Magnet Motors with Semi-Closed Slots. IEEE Trans. Magn. 2011, 47, 479-492. [CrossRef]

39. Lubin, T.; Mezani, S.; Rezzoug, A. Exact Analytical Method for Magnetic Field Computation in the Air Gap of Cylindrical Electrical Machines Considering Slotting Effects. IEEE Trans. Magn. 2010, 46, 1092-1099. [CrossRef]

40. Fitzgerald, A.E.; Kingsley, C.; Umans, S.D. Electric Machinery; McGraw-Hill: New York, NY, USA, 2003. 